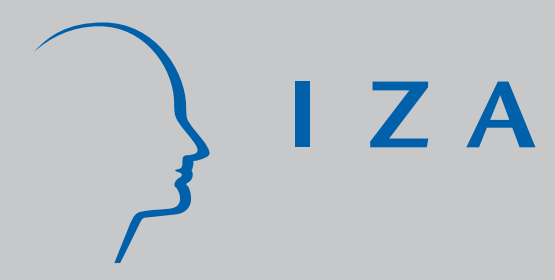

IZA DP No. 3217

Immigrant Networks and Their Implications for Occupational Choice and Wages

Krishna Patel

Francis Vella

December 2007 


\title{
Immigrant Networks and Their Implications for Occupational Choice and Wages
}

\author{
Krishna Patel \\ Georgetown University \\ Francis Vella \\ Georgetown University \\ and IZA

\section{Discussion Paper No. 3217 \\ December 2007} \\ IZA \\ P.O. Box 7240 \\ 53072 Bonn \\ Germany \\ Phone: +49-228-3894-0 \\ Fax: +49-228-3894-180 \\ E-mail: iza@iza.org
}

\begin{abstract}
Any opinions expressed here are those of the author(s) and not those of the institute. Research disseminated by IZA may include views on policy, but the institute itself takes no institutional policy positions.
\end{abstract}

The Institute for the Study of Labor (IZA) in Bonn is a local and virtual international research center and a place of communication between science, politics and business. IZA is an independent nonprofit company supported by Deutsche Post World Net. The center is associated with the University of Bonn and offers a stimulating research environment through its research networks, research support, and visitors and doctoral programs. IZA engages in (i) original and internationally competitive research in all fields of labor economics, (ii) development of policy concepts, and (iii) dissemination of research results and concepts to the interested public.

IZA Discussion Papers often represent preliminary work and are circulated to encourage discussion. Citation of such a paper should account for its provisional character. A revised version may be available directly from the author. 


\section{ABSTRACT \\ Immigrant Networks and Their Implications for Occupational Choice and Wages}

This paper employs United States Census data to study the occupational allocation of immigrants. The data reveal that the occupational shares of various ethnic groups have grown drastically in regional labor markets over the period 1980 to 2000 . We examine the extent to which this growth can be attributed to network effects. That is, we examine the relationship between the occupational choice decision of recently arrived immigrants with those of established immigrants from the same country. We also consider the earnings implications of these immigrant networks for recent arrivals. The empirical evidence strongly suggests the operation of networks in the immigrant labor market. First, we find evidence that new arrivals are locating in the same occupations as their countrymen. Moreover, this location decision is operating at the level of regional labor markets. Second, we find that individuals who locate in the "popular" occupations of their countrymen enjoy a large and positive effect on their hourly wage and their level of weekly earnings.

JEL Classification: J24, J3, J61

Keywords: network effects, immigrants, occupational choice, earnings

Corresponding author:

Francis Vella

Department of Economics

Georgetown University

Washington, DC 20057

USA

E-mail: fgv@georgetown.edu

\footnotetext{
* We are grateful to Jim Albrecht, Pieter Gautier and seminar participants at UBC and Ente Einaudi for helpful comments. This paper replaces an earlier version which was circulated under the same number until April 2008. In addition to correcting a coding error related to the results in Section 6 we provide additional results via an alternative identifying strategy.
} 


\section{Introduction}

In 1980 0.68\% of all hairdressers and cosmetologists in the Houston-Brazoria metropolitan area were born in Vietnam. By 1990 this percentage had grown to $6.21 \%$ and by 2000 it was $24.18 \%$. In Fort Lauderdale, $4.00 \%$ of food preparation workers in 1980 were from Haiti. This share increased to $23.52 \%$ in 1990 and to $26.56 \%$ in 2000 . While each of these trends is remarkable they are not atypical. An examination of the occupational allocation decisions of immigrant workers in metropolitan areas suggests that all across the United States, immigrants from a range of countries have developed local niches in specific occupations.

If such a phenomena is occurring on a larger scale, and this is one question we address here, it is useful to consider potential explanations of this remarkable occupational concentration. First, the 1965 amendment to the US Immigration Act eliminated country specific quotas and produced a large increase in the number of immigrants. ${ }^{1}$ This increase would explain a general growth in their share of some occupations providing that; i) the native born population did not increase at the same rate; and/or ii) the new immigrants were not allocated across occupations in a manner which preserved the previous allocation. A second explanation is related to the skill portfolios that accompany immigrants. If there was a drastic increase in the number of migrants from a particular country and these migrants all had a specific skill(s), it is likely that their share of occupations that require that skill would increase accordingly (see, for example, Roy 1951). Third, it is possible that local labor markets are experiencing occupation specific shocks and this is generating increased labor demand in these occupations. If immigrants are more mobile than natives it is likely they will locate in these newly created positions (see Borjas 2001).

While each of the above would appear to at least partially contribute to the observed trends in occupational concentration by immigrants the drastic trends noted above, and many others we detail below, seems suggestive of an additional process. That is, the growth of the number of immigrants from various countries in a range of occupations suggests that new immigrants are following their countrymen and finding employment in the same occupations. We interpret this occupational location decision as the product of a network effect. Establishing the presence of such

\footnotetext{
${ }^{1}$ The country specific quotas were replaced with a world-wide limit on immigrants. In 1996 the visa limit was 507,000 , of which $62 \%$ were for family reunification. Immediate family of US citizens are exempt from immigration quotas and in the mid 1990s over 70\% of immigrants came under family reunification (Borjas 1999).
} 
an effect is an important exercise as it has obvious welfare implications for immigrants if it leads to employment opportunities. Network effects would be even more economically significant if they had implications for wages and earnings.

In this paper we attempt to identify and estimate the magnitude of one specific form of immigrant network effects on the occupational allocation of immigrants using United States Census data for the years 1980, 1990 and 2000. More explicitly we examine if the occupational choices of recently arrived immigrants are influenced by the occupational location of their predecessors. We also investigate the empirical implications of these networks for the wages and weekly earnings of recent immigrants. As the occupational choices and wages of recent immigrants are likely to be endogenously determined with the occupational choices of established migrants we adopt two identifying strategies. We first instrument the occupational distribution of the established migrants with that of migrants in the same region in the prior census. While this identifying strategy may be questionable if there are time persistent regional effects which affect the occupational choice of particular groups we feel it is appropriate here due to the conditioning variables we include in the specifications we adopt and the relatively low level of skill required for the occupations which are overwhelmingly chosen by new immigrants. Nevertheless we supplement our primary findings with those from an alternative identifying strategy based on the construction of pseudo panel based on average regional behavior which is defined precisely to account for any time persistent regional effects which are group specific.

In the following section we discuss the literature relevant to network effects and occupational choice. Section 3 provides a simple labor market search model which incorporates a role for immigrant networks. Section 4 discusses our data and sample selection. Section 5 documents the trends in occupational shares by immigrant groups in local labor markets while Section 6 reports the estimates from a model which explains the probability that a recently arrived immigrant will choose the occupation most commonly adopted by previous immigrants from his/her country. Section 7 explores whether there are any wage and earnings implications from this location decision. Section 8 provides a more detailed discussion of our empirical results. Section 9 provides some concluding comments. 


\section{Literature}

In reviewing the literature related to the role of networks in the occupational choice decision we begin with our use of the term "network" and the precise effect we seek to uncover in our empirical investigation. We assume that individuals that come from the same country and who are located in the same metropolitan area are likely to have a relatively higher propensity to interact. This may reflect common acquaintances in the US or their home country, or their common cultural background. We now briefly examine the existing literature, both theoretical and empirical, which explains how this type of network membership might influence an individual's propensity to take employment in the same occupation as the other network members. These effects are likely to operate through an individual's employment search method and also the level of potential job offers. It is also a way of acquiring job offers (see, for example, Montgomery 1991). For employers these networks may represent a mechanism for screening potential workers.

Previous empirical evidence has established that networks are important in influencing individual employment outcomes. For example, 17\% of those unemployed workers surveyed in the 1970 Current Population Survey (CPS) consulted friends and relatives for work. This figure grew to $23 \%$ in the 1991 CPS (Bradshaw 1973, Bortnick and Ports 1992, Ioannides and Datcher Loury 2004). Networks are useful for both employed and unemployed workers both in terms of frequency of job offers and acceptance (Blau and Robins 1990, Blau 1992). Over a range of data sets it was found that between 30 to 60 percent of job matches were made through personal ties, with a greater prevalence of network use among low skilled workers (Ioannides and Datcher Loury 2004).

Several theoretical studies investigate the impact of the dissemination of information through networks on job search. While job information acquired through networks generally improves both the individual's probability of employment and wage level there are circumstances under which they might both decline (Calvo Armengol and Jackson 2003, 2004). The empirical evidence, however, generally suggest that networks improve the probability of employment of its members (see Munshi 2003, Beaman 2007, Laschever 2007). The evidence further suggests that a network defined by geographic proximity has a positive influence on individual employment. These neighborhood effects tend to be particularly strong between ethnically similar locations (see Bayer et al 2004, Topa 2001, Laschever 2007). For example, Edin et al (2003) show a large and positive income effect 
for immigrant refugees living in ethnic enclaves in Sweden.

The empirical economics literature on networks in the labor market has focused either on unemployment or wages while largely ignoring occupational choice. The sociology literature, however, discusses the importance of immigrant networks in developing occupation niches. These studies are generally historical in nature and suggest that immigrant groups which shared employment opportunities through their networks perform better in terms of obtaining employment in higher paid occupations (Model 1993). Waldinger (1996) suggests that the rapid movement of white native workers away from certain jobs in New York city enabled ethnic minorities to form niches. Networks then channeled immigrants of specific ethnic backgrounds into specific occupations. Waldinger (1994) studied immigrant workers in New York City's government, a sector in which immigrants started to emerge more prominently during the latter part of the twentieth century, and finds that immigrants sorted into different occupations within city government according to ethnic background. Some empirical studies, (see, for example, Logan, Alba and Zhang 2002), suggest that immigrants choose their occupation after choosing their location. Since a majority of immigrants are based on family re-unification their location decisions, and subsequently their occupational choices, are constrained (Parks 2005).

One economic investigation of interest is Munshi and Wilson (2007) which explores the influence of the occupational choice of nineteenth century immigrants on those of current immigrants from the same country. The focus of that paper is on cultural identity defined by the occupation choice of the first generation of immigrants. The empirical component of the paper focuses on the probability of accepting a high skilled job over a low skilled job.

\section{Conceptual Framework}

To motivate the empirical work that follows we present a simple model of the search behavior of immigrants. The unemployed are able to search for a job and this may take place through formal channels such as newspaper advertisements or online postings. Alternatively, the search may occur through informal channels. We define the informal channel as the individual's network of employed friends and relatives.

Let $S$ denote the set of occupations for which individual $i$ is qualified. Let $S^{N}$ denote the set 
of occupations included in his network for which the individual is qualified. Therefore, $S^{N} \subset S$. Assume a continuous time model in which job offers follow a Poisson process and can arrive from either channel. Jobs offers in occupation $o$ arrive via the formal channel with arrival rate $p_{o}$, while they arrive in occupation $o$ via the network at rate $p_{o}^{N}$.

We assume that recently arrived immigrants seek to maximize the expected value of discounted future income using discount rate $r$. While unemployed the individual receives $b$ through unemployment compensation or leisure. Since there is a distribution of wages offered in occupation $o$, the individual does not know the actual wage offered ex-ante. Let $w_{o}$ represent the wage offered through the formal channel in occupation $o$ with distribution $F_{o}\left(w_{o}\right)$, and $w_{o}^{N}$ represent the wage offered in occupation $o$ through the network channel with distribution $F_{o}^{N}\left(w_{o}^{N}\right)$. When employed in occupation $o$ the individual receives wage $w_{o}$, or alternatively $w_{o}^{N}$, forever. The value of working in a job found through the formal channel and the informal channel can be defined, respectively, as $W\left(w_{o}\right)=\frac{w_{o}}{r}$ and $W\left(w_{o}^{N}\right)=\frac{w_{o}^{N}}{r}$. The value of being unemployed can thus be expressed as:

$$
r U=b+\sum_{o \in S} p_{o} \int \max \left[W\left(w_{o}\right)-U, 0\right] d F_{o}\left(w_{o}\right)+\sum_{o \in S^{N}} p_{o}^{N} \int \max \left[W\left(w_{o}^{N}\right)-U, 0\right] d F_{o}^{N}\left(w_{o}^{N}\right)
$$

The first term in this expression represents the flow value of unemployment. The second and third terms capture the expected values from being employed when the job offer arrives from the formal and network channels respectively, noting that the expectation is taken over the wages offered in occupation $o$ through each channel. Once the individual encounters a job with wage realization $w_{o}\left(\right.$ or $\left.w_{o}^{N}\right)$, he/she would accept a job offer if $W\left(w_{o}\right)\left(\right.$ or $\left.W\left(w_{o}^{N}\right)\right)$ is greater than $U$.

The arrival rate of a job offer in occupation $o$ from the network channel is directly proportional to the number of people in the network who are employed in occupation $o$. Assume $n_{o}$ represents the number of people in the individual's network who are employed in occupation $o$ and all individuals in the network face the same arrival rate $p_{o}$. Then $p_{o}^{N}$ can be expressed as:

$$
p_{o}^{N}=\sum_{i \in n_{o}} p_{o}^{i}=n_{o} p_{o}
$$

When confronted with a job offer in occupation $o$, the individual will accept the offer provided 
the offered wage, $w_{o}$, is at least as large as his/her reservation wage. The reservation wage is the wage that makes the individual indifferent between being employed and being unemployed and solves $W\left(w_{R}\right)=U$. Rearranging, and noting that $W\left(w_{o}\right)=\frac{w_{o}}{r}$, implies $r U=w_{R}$ and $W-U=\frac{w-w_{R}}{r}$. Inserting this into equation (1) and simplifying gives the following expression for the reservation wage:

$$
w_{R}=b+\sum_{o \in S} p_{o} \int_{w_{R}} \frac{w_{o}-w_{R}}{r} d F_{o}\left(w_{o}\right)+\sum_{o \in S^{N}} p_{o}^{N} \int_{w_{R}} \frac{w_{o}^{N}-w_{R}}{r} d F_{o}^{N}\left(w_{o}^{N}\right) .
$$

Simplifying (3) further gives

$$
w_{R}=b+\frac{1}{r} \sum_{o \in S} p_{o} \int_{w_{R}}\left[1-F_{o}\left(w_{o}\right)\right] d w_{o}+\frac{1}{r} \sum_{o \in S^{N}} p_{o}^{N} \int_{w_{R}}\left[1-F_{o}^{N}\left(w_{o}^{N}\right)\right] d w_{o}^{N} .
$$

Using equations (2) and (4) the following results can be obtained. First, since the overall arrival rate of a job in occupation $o$ can be expressed as $P_{o}=p_{o}+p_{o}^{N}$, then $\frac{\partial P_{o}}{\partial n_{o}}=p_{o}>0$. That is, the overall arrival rate of a job in occupation $o$ increases in the number of people in the network who are employed in occupation $o$.

Second, applying the implicit function theorem to (4) suggests that the reservation wage is increasing in the number of people in the network employed in occupation $o, \frac{\partial w_{R}}{\partial n_{o}}>0$. To see this, note that the reservation wage is increasing in the arrival rate of job offers, a result that is standard in search models. Since the arrival rate of job offers in occupation $o$ is increasing in the network size in occupation $o, n_{o}$, the reservation wage is also increasing in $n_{o}$. Intuitively, if individuals encounter more job offers, they become more selective about the jobs they will accept. We would expect individuals with a higher reservation wage to accept higher wage jobs on average.

Furthermore, "clustering" in occupation $o$ would arise when acceptable offers in occupation $o$ arrive from the network channel at a faster rate than acceptable job offers in any other occupation that arrive through the formal channel. That is, when $p_{o}^{N} \operatorname{Pr}\left(w_{o}^{N}>w_{R}\right)>\sum_{k \in S} p_{k} \operatorname{Pr}\left(w_{k}>w_{R}\right)$. This occurs when either $n_{o}$ is large or when $\operatorname{Pr}\left(w_{o}^{N}>w_{R}\right)>\operatorname{Pr}\left(w_{k}>w_{R}\right), \forall k \neq o$ or both.

While the above model is simple and is presented primarily to motivate our examination of the data, it provides two clear predictions. First, the probability an individual will locate in an occupation is a function of the size of the individual's network in that occupation. Second, the 
individual's reservation wage, and by implication the accepted wage, is positively related to the size of the individual's network in the occupation.

\section{Data and Key Variable Definitions}

To examine the growth in occupational shares we employ the five percent samples from the 1980, 1990 and 2000 US Censuses. While the census is only available at ten year intervals, it provides a sufficiently large number of observations to identify occupational growth patterns in the various regions comprising the US. The occupation codes used are based on the variable "occ1990" which characterizes the individual's occupation at the three digit level. ${ }^{2}$ This variable has approximately 300 classifications, based on the 1990 occupation classification scheme, and is comparable across the years we consider.

In our empirical analysis we distinguish between 'new' immigrants and 'established' immigrants as we focus on the empirical relationship between the occupational choices of these two groups. Although it would be most useful to observe the occupation of the immigrant's first job entering the US, such detailed work history variables are not available. The most recent immigrant group which can be distinguished in the 1980 census are those individuals who have arrived in the United States between 1975 and 1980. For the 1990 census, the most recent identifiable immigrants are those who immigrated in 1987. For the 2000 census, it is those arriving after 1998. To retain consistency across samples we define those individuals who arrived in the US within five years of the survey date to be 'new' immigrants. All remaining foreign born workers, comprising those who have immigrated over five years prior to the survey date, are considered 'established' immigrants. While this dichotomy is determined by the limitations of the data it does not seem unreasonable. That is, determining what distinguishes 'established' from 'new' is arbitrary and the most important requirement is that one can identify recent arrivals. The five year distinction does not seem unreasonable for our purposes.

To examine occupational growth by immigrant groups in local labor markets it is necessary to have an operable definition of a local labor market. We define it to be a metropolitan area. There are roughly 292 such areas identified in the census although the exact number varies by census year. For the 2000 Census immigrant sample, 72,614 observations of 818,083 live in an unidentified

\footnotetext{
${ }^{2}$ This measure is preferable to the occ1950 variable, also available for each of the years we consider, as it provides a more recent occupation classification scheme.
} 
metropolitan area, compared to 124,291 observations that work in an unidentified metropolitan area. We employ the metropolitan area of the workplace as our measure of where the individual is located as this seems the better measure for our purposes.

As the data comprises a large number of occupations and an equally large number of metropolitan areas, and we also make a distinction within the immigrants on the basis of their country of birth, small cell sizes are likely to be an issue. To describe the patterns in the data we initially include observations for every metropolitan area which has at least 100 workers. However, we subsequently focus our analysis on those immigrants who are employed in an identified occupation in an identified metropolitan area where there at least 100 other immigrants from their country in that metropolitan area. This selection criteria produces a very large data set, in terms of numbers of individuals, and includes about 100 metropolitan areas and immigrants from approximately 100 countries working in over 250 occupations.

While our attention is initially on occupational allocation, we subsequently focus on the impact of network membership on wages. The census includes measures of annual wages, weeks worked and usual hours worked per week for the previous calendar year. This allows the construction of an individual's hourly wage. This constructed hourly wage variable appears to be susceptible to measurement error at extreme points in the distribution. Accordingly we trim the data by eliminating observations which are in the top and bottom $0.1 \%$ of the wage distribution. The descriptive statistics for our sample are provided in Appendix Tables A4.1 and A4.2.

\section{Occupation Shares by Country of Origin}

To explore the growth in the occupational shares of ethnic groups in local labor markets Tables 5.1 and 5.2 report these shares for different origin countries at both the metropolitan and national level. We reiterate that we only include occupations that had at least 100 observations in the metropolitan area during at least one of the census years.

The first section of Table 5.1 presents the proportion of working individuals from country $j$ in area $m$ in occupation $o$ for each of the census years. The second section of the table reports the proportion of those working in area $m$ in occupation $o$ who are from country $j$. It is these two features of the data in which we are most interested. The first captures the tendency of individuals 
from certain countries to go into specific occupations and reflects the network phenomenon which is suggested by the conceptual model above. The second section reports the rate at which this network effect is resulting in the domination of certain occupations in various regions by different ethnic groups. The third section of the table reports the change over the three census years for the estimates in the second section of the table. Table 5.1 also reports the country of origin population as a percent of total population in the metropolitan area. Note that due to the extremely large number of cells it is not possible to list each of them. Accordingly, for presentational purposes we adopt the following strategy. For each country group in each area we tabulate the five most popular occupations. This produces a list of 3,361 cells. We then rank these cells on the basis of their growth in occupation share over the period 1980 to 2000 and list those at every second percentile. ${ }^{3}$ For example, the first entry reports that Chinese textile workers who work in the New York-Northeastern New Jersey metropolitan area had a change in occupation share at the 99-100 percentile. Their percentage share of that occupation in 1980 was 17.26 and this grew to 43.78 by 2000.

We acknowledge that Table 5.1 reports excessive information to be easily absorbed by the reader. We present it to illustrate the range of countries, metropolitan areas and occupations which experience notable growth. The table also reveals that while the two examples discussed in this paper's opening paragraph are the most dramatic there are a number of occupation/immigrant group cells which have seen extraordinary growth in certain areas. Moreover, this growth is not limited to a small number of occupations. We pursue this below.

Table 5.2 provides the occupation shares for country groups that experienced the fastest growth over 1980-2000. To illustrate that this phenomenon is not simply due to immigrants from Mexico, who figure prominently in Table 5.1, we exclude them from this table. Table 5.2 suggests other ethnic groups are also obtaining a growing share of certain occupations in local labor markets. It appears the dramatic growth in occupation shares for these immigrant groups occurs primarily at a metropolitan area level, as the corresponding occupation shares at the national level are relatively modest and do not demonstrate clear patterns. Moreover, while many of these metropolitan areas have a high proportion of immigrants, the growth in occupation share for the country groups is disproportionate to its growth in population. Tables 5.1 and 5.2 suggest there is no clear rela-

\footnotetext{
${ }^{3}$ When there were multiple cells at each of the reported percentiles we chose one at random.
} 
tionship between metropolitan area population share and occupation share. A high share in a particular occupation for a country group in one metropolitan area does not imply a high share in the same occupation elsewhere. While this partially reflects regional variation in the distribution of occupations it is interesting nevertheless. One particularly striking example, illustrated in Table 5.2 , is that of textile sewing machine operators in New Bedford, MA. This metropolitan area has a large but declining population of Portuguese workers which initially grew from $12.23 \%$ in 1980 to $17.82 \%$ in 1990 before decreasing to $10.22 \%$ in 2000. The proportion of Portuguese in this occupation grew steadily from $55.43 \%$ in 1980 to $69.42 \%$ in 1990 to $71.15 \%$ in 2000 . It is also interesting that the data indicates that this occupation is dominated by Chinese or Mexican workers in other metropolitan areas. The fact that Chinese or Mexican workers in the textile occupation are practically absent in New Bedford, MA while Portuguese workers are absent in the textile occupations in other metropolitan areas suggests that this observed specialization in local labor market is not based on home country specific skills.

As the occupations which appear in these tables generally require a relatively low level of specialized training this might reflect that the strong presence of a country group in an occupation is not the result of comparative advantage. To investigate this Table 5.3 presents for each country of origin, the number of unique occupations that ranked as the most popular occupation across metropolitan areas. The most popular occupation in a metropolitan area is defined to be the occupation that has the highest fraction of that country's members. For example, there were 18 distinct most popular occupations for Puerto Rican workers across all metropolitan areas in the year 2000. The first set of columns represent the number of unique occupations that were ranked the highest for each country group across all metropolitan areas. These numbers are somewhat misleading because not every country group is represented in all metropolitan areas. Additionally, multiple occupations were frequently tied for the top occupation rank in which case all tied-occupations were counted. Therefore, the second set of columns represents a normalized measure of the distribution of top ranked occupations. It represents the number of unique occupations that are top ranked across metropolitan areas divided by the number of metropolitan areas in which the country group is present. This number can exceed 1 when multiple occupations tie for the top rank. Overall, a higher number suggests a higher dispersion of most popular occupation categories across metropolitan areas. For most countries the occupation dispersion is well above 0.5 indicating there 
is substantial variation in the preferred occupational location of each ethnic group. ${ }^{4}$ While this variation may reflect "within" variation in the composition of immigrant groups across metropolitan areas (i.e. people from the same country may select different metropolitan areas based on their skill set), it is unlikely to explain why one low skilled occupation is popular among a country group in one metropolitan area while another occupation is popular elsewhere. This table is important for our purposes in that it suggests that the occupational choice of immigrants is not based purely on comparative skill advantages.

\section{An Empirical Model of Immigrant Occupational Allocation}

To establish the underlying determinants of occupational location one could estimate a multinomial choice model where each of the occupations in the potential choice set represents a different outcome. However, given that behavior in which we are interested occurs at a relatively disaggregated level this would require estimating a discrete choice model with an extremely large number of outcomes. This would not be feasible without the imposition of a large number of unreasonable economic and statistical restrictions. Accordingly we focus on one particular aspect of the occupational allocation decision of immigrants which is implied by our conceptual model in Section 3. We examine whether a new arrival chooses the dominant occupation for his/her immigrant group in the region in which he/she has arrived. That is, we estimate the following:

$$
\operatorname{Pr}\left(I_{i j m o t}=1\right)=\alpha+\gamma_{1} Y_{j m o t}^{\text {estab }}+\gamma_{2} Y_{n m o t}+\gamma_{3} S_{m o t}+X_{i t} \beta+\eta_{i j m o t}
$$

where $I_{i j m o t}$ is an indicator function denoting that immigrant $i$ from country $j$ who locates in metropolitan area $m$ chooses occupation $o$ in time period $t$. The choice of occupation depends not only on the country from which the individual comes but reflects the most commonly chosen occupation for that immigrant group in that metropolitan area prior to the arrival of the new immigrants. The independent variable $Y_{j m o t}^{\text {estab }}$ measures the percent of people from country $j$ working in metropolitan area $m$ of established immigrants who are in occupation $o$. This variable captures our defined network effect and its coefficient $\gamma_{1}$ is the object of primary interest. We also include $Y_{n m o t}$ which measures the proportion of people in that occupation $o$ in metropolitan area $m$ who

\footnotetext{
${ }^{4}$ The weighted average of this measure was approximately .3 for each of the Census years.
} 
are native born. This variable captures the propensity of the occupation in that area to employ immigrants (natives). To capture the relative size of the occupation we also include $S_{m o t}$ which denotes the proportion of workers in area $m$ who are employed in occupation $o$ in time $t$. We also include a number of the individual's characteristics, such as age, education, marital status, gender and his/her capacity to speak English. In addition we include indicator functions for the individual's country of origin and the metropolitan area and region in which the individual works. These country of origin variables are likely to capture any ethnic preference regarding occupation while the region and metropolitan area dummies are included to capture unobserved demand effects. Finally, $\eta_{i j m o t}$ is assumed to be a zero mean error term. Note, however, we do not include interaction terms involving the metropolitan area and country of birth.

Before proceeding consider the expected values of the coefficients in (5). First, as the estimated models include regional and metropolitan indicators and country of origin dummy variables, the model controls for the propensity of all immigrants in a specific area to locate the occupation which is the most popular for that region. It also accounts for the propensity of all individuals from a particular country to locate in an occupation which is the most popular of their countrymen. Moreover, in the case of simple random allocation, after conditioning on the included human capital variables, the probability of locating in the most popular occupation will be strongly related to the proportion of people already in that occupation in that metropolitan area. Accordingly, while it is difficult to sign the coefficients for the metropolitan area and country of origin dummies the variable $S_{m o t}$ would have a coefficient of one if individuals went into the occupations purely on the basis of the available jobs. Most importantly, there is no reason to suspect, given the other variables which are included on the RHS of (5), that the coefficient $\gamma_{1}$ should be non zero in the absence of network effects.

An obvious objection to the OLS estimation of (5) is the endogeneity of the key regressor $Y_{j m o t}^{\text {estab }}$. It is possible that unobservable factors, such as labor demand shocks, simultaneously influence the occupational choices of new and established immigrants. It is also possible, although less likely, that the causality operates in the opposite direction. That is, the established workers may be relocating depending on where the new arrivals find employment. The presence of unobservable factors and/or reverse causality would bias our estimates. Accordingly we instrument $Y_{j m o t}^{\text {estab }}$ with $Y_{j m o t-10}^{\text {estab }}$ which denotes the occupational share of workers from country $j$ in metropolitan area $m$ in occupation $o$ ten 
years prior to the census for time $t$. This captures the occupational choices of an older generation of immigrants that were made before the arrival of the new immigrants. These instruments are highly correlated with the endogenous explanatory variables and have highly significant F statistics in the corresponding first stage regressions. ${ }^{5}$ As the same objections may arise with respect to $Y_{n m o t}$ and $S_{m o t}$ we use the same instrumenting strategy for these two variables.

We acknowledge that the use of these types of "lagged" instruments is frequently seen as controversial. This is not because of a "weak instrument" concern but rather because they are seen as invalid. For example, one might argue that there are unobservables, or omitted variables, which are correlated with the occupational distribution of migrants from a specific country in a particular metropolitan area in year $t$ which are correlated with those in year $t-10$. Our identifying assumption is not that there are no such factors, but that they do not remain after we condition on the variables in our model. As this assumption is crucial to our empirical work it is important that we are able to convince the reader of the validity of this assumption.

First, this type of unobserved skill problem might arise when immigrants are locating in certain metropolitan areas on the basis of their skills. As discussed above the majority of immigrants are obtaining entry on the basis of family reunification and thus it seems likely that the initial location decision is exogenous to occupational choice. Second, a problem of this type might arise if they were some specific unobserved skill which: i) was commonly found in immigrants from a certain country, and ii) was in high demand in certain regions of the country. An examination of the Table 5.1 indicates that the majority of occupations which appear as the most popular are frequently low skilled occupations. This would appear to be inconsistent with an objection based on an argument related to unobserved skills. Moreover, as we discuss below, the "unobserved skill" argument would also be consistent with immigrants from certain countries specializing in certain occupations. We show below that this is inconsistent with the data in that immigrants from the same origin country are specializing in different occupations depending on where they locate. While this may reflect that they have "many" unobserved skills, the fact that they are generally specializing in low skilled occupations appears to work against this possibility. Finally the argument above requires that there

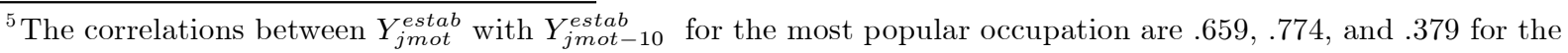
years 2000, 1990 and 1980 respectively. Note that when any particular cell was empty in the prior census we employ the value 0 as the instrument. However, when the metropolitan region was non existent in the previous census the observation was deleted. This explains the difference in the number of observations used in the OLS and IV samples.
} 
are country of origin and metropolitan area interaction effects which persist over time. Given that there are over 100 countries of origin and over 250 metropolitan areas this would require estimating a huge number of additional parameters and this seems unreasonable. Accordingly, we attempt to somewhat capture such effects by including country origin and metropolitan dummies. Invalidity of our instruments requires that these additional interaction effects should appear in the choice equation after we have included the country of origin and metropolitan area dummies as well as the extensive conditioning set. Once again, the low skilled nature of the majority of occupations being chosen makes this unlikely.

While we are confident that our identification strategy is reasonable we also supplement our results with an alternative identifying strategy which focusses precisely on the presence of these interaction effects. That is, rather than examining the individual level we aggregate the data to the country of origin by metropolitan area level. More precisely we specify:

$$
\operatorname{Percent}\left(I_{j m o t}=1\right)=\alpha+\gamma_{1} Y_{j m o t}^{\text {estab }}+\gamma_{2} Y_{n m o t}+\gamma_{3} S_{m o t}+\bar{X}_{j m t} \beta+\eta_{j m o t}
$$

where $\operatorname{Percent}\left(I_{j m o t}=1\right)$ denotes the proportion of new immigrants from country $j$ in metropolitan area $m$ who chose the popular occupation $o$ in time $t$; the variables $Y_{j m o t}^{\text {estab }}, Y_{n m o t}$, and $S_{m o t}$ are defined as above and the $\bar{X}_{j m t}$ denotes the average characteristics of immigrants from country $j$ in area $m$. Note that the coefficient $\gamma_{1}$ still has the interpretation of how the proportion of established immigrants affects the probability of recently arrived immigrants locating in the most popular occupation. In the presence of these unaccounted interaction effects the error term in (6) has the form:

$$
\eta_{j m o t}=\delta\left(\varepsilon_{j} * \nu_{m}\right)+\epsilon_{j m o t}
$$

where the $\varepsilon_{j}$ denotes country of origin effects, $\nu_{m}$ denotes the metropolitan area effects, $\delta$ is an unknown parameter, and $\epsilon_{j m o t}$ is zero mean noise. Recall that in the original specification the country of origin and metropolitan area effects are captured by dummies. Using the (6) specification we now proceed by constructing the variables for two periods and then taking deviations from the means for the two periods. This panel data procedure eliminates all the country of birth and metropolitan area effects including the interaction effects captured in $\delta\left(\varepsilon_{j} * \nu_{m}\right)$. This allows us 
to identify $\gamma_{1}$ in the presence of these time persistent effects. Naturally this is done at the cost of losing the variation across $i$. It does, however, provide an estimate which is consistent in the presence of the above concern.

We first estimate (5) separately for the 1980, 1990 and 2000 census data. In each model the unit of observation is the individual and the number of observations per cross section is shown in Table 6.1. While the unit of observation is the individual for each cross section the variable $Y_{j m o t}^{\text {estab }}$ shows variation by area, occupation and immigrant group while $Y_{n m o t}$ and $S_{m o t}$ vary by metropolitan area and occupation.

The dependent variable in equation (5) takes the value 1 if the individual is working in the most popular occupation of the people from his/her country in the metropolitan area where he/she works. We denote this outcome in the tables as occpop1. Given the large number of occupations it is possible that there may be several "equally" popular occupations for each immigrant group in each region. Accordingly, we re-estimate the model where we define a series of dependent variables corresponding to the events that the individual selected an occupation among the most popular two, the most popular three, the most popular four and finally the most popular five (occpop5). The independent variables are also redefined to reflect this change when appropriate.

In evaluating how immigrant networks affect occupational allocation in the United States the treatment of observations of Mexican workers is likely to be important. Mexican workers currently comprise 25.57 percent of all immigrant workers and their long and substantial presence in the US labor market suggests that they have established networks in the US (see, for example, Munshi 2003). Accordingly, we explore the impact of excluding Mexican workers from the left hand side of the regression although we include them in constructing the conditioning variables.

Table 6.1 presents the instrumental variables estimates for the variables of primary interest for the sample including Mexicans. Table A6.1b in the appendix reports the full set of estimates and for the sake of comparison we report the OLS estimates in Table A6.1a. The argument in favor of endogeneity seems convincing in this context, a conjecture that is supported by the statistical tests comparing the OLS and IV estimates, and as such we focus directly on the IV estimates. Note however, that despite the strong statistical rejections of exogeneity, partially due to the large number of observations, the parameter estimates for the OLS and IV estimates of the parameters are similar except for the 1980 census. The estimates for this cross section rely on the 1970 
census for the construction of the instruments and due to the far smaller cell sizes employed in the construction of the estimates, the resulting parameter values are more erratic. ${ }^{6}$ Accordingly, we only report the IV estimates for 1990 and 2000 although we also include the OLS results for 1980 to show the similarity across years.

The various columns of the tables that follow represent the estimates for each of the census years and where the outcome variables corresponding to the most popular and five most popular occupations are employed. ${ }^{7}$ A number of results are worth noting. The most remarkable, however, is that related to the network parameter $\gamma_{1}$. For each of the definitions of the occupational outcome and for each census year the parameter estimate is approximately 1 and has a very large t-statistic. Recall that the network effect is consistent with any non zero estimate. The estimated coefficients suggest that recently arrived immigrants are more likely to enter the same occupations as those in which the countrymen are located. Moreover, the typical coefficient reflects a large economic effect. For example, the coefficients for the uniquely defined outcome is 1.15 in 2000 and 1.94 in 1990. This indicates that if the proportion of the previous immigrants from a certain country that are located in a certain occupation group in a certain region increased by 1 percentage point the probability that a new immigrant from that country would locate in that occupational group increases by approximately 1 to 2 percentage points in this two periods. This is a substantially important economic effect if we recall that the occupational distribution of the metropolitan area is already accounted for via the inclusion of other variables and these effects simply reflect the network effect. Also note that the magnitude of the effect does not change much as we expand the number of occupations in the dependent variable. This suggests that network effects operate in a range of occupations for each ethnic group in each region. There is, however, some decrease in the magnitude of the estimates as well as loss in its precision.

Focus now on the variables capturing the share of the occupation and the presence of native born in the occupation. The relative size of the occupation generally has a negative coefficient but its coefficient is not always statistically significant. The coefficient on the proportion of native born in the occupation does not display any clear pattern and is generally statistically insignificant. This

\footnotetext{
${ }^{6}$ The source of the problem with the 1980 IV estimates is they employ the 1970 values as instruments. For this particular cross section there was a large number of empty cells and the use of zeros for all of these cells reduced the amount of information contained in the instrument.

${ }^{7}$ The results for the top two, top three and top four occupations are also reported in the appendix tables.
} 
suggests that the size of the network is a more important factor than these two other influences.

As noted above, we also include in the regressions a number of variables to control for specific characteristics of the individual. However, before we focus on these variables we consider the estimates on the network related variables using the sample which excludes Mexican immigrants from the left hand side (LHS) of the regression. The pattern of the results, reported in Table 6.2, is similar to those for the whole sample although there are some important differences. For the uniquely defined outcome the coefficient is 0.707 in 2000 and 2.086 in 1990 . For the top 5 outcomes the estimates are 1.135 and 1.559 respectively. The coefficients for the other variables capturing the size and proportion which is native of the occupation generally show the same patterns as those for the entire sample.

Now focus on the role of the individual's characteristics noting that the results are qualitatively the same for both samples. Some of the estimates are reported in the appendix Tables A6.1b and A6.2b. Although they are not reported here, the coefficients on age and age squared reveal that there is a relatively unimportant role of age, both in economic and statistical significance, on choosing the most popular occupation. The role of gender is generally ambiguous and the sign changes from year to year and according to specification of the dependent variable. It is likely that as many occupations are dominated by one gender the sign of the coefficient primarily reflects the composition of the occupations in the dependent variable. The coefficients for the variables capturing the marital status of the individual do not reveal any remarkable effects.

Consider the human capital variables. The ability to speak english well has a negative coefficient and is statistically significant effect for the outcomes shown in Tables A6.1b and A6.2b. In these instances this may reflect that workers who cannot speak english well are more reliant on personal contacts when finding employment. Alternatively it is possible that individuals who cannot speak english well are more productive when surrounded by individuals from the same nationality and thus locate in occupations accordingly. The coefficient on the education of the individual is generally statistically significant but does not display any clear pattern. The mean education level of the occupation generally has a negative statistically significant effect.

The estimation results appear to strongly support the conjecture that immigrant network effects are operating in local labor markets. Moreover, in addition to being estimated with some precision the effects appear large and important. Moreover, as the effects are very similar going back to the 
1980 census (on the basis of the OLS estimates) it appears these immigrant network effects are firmly entrenched in the US labor market.

While the results seem persuasive they are reliant on the assumption that the instruments are valid. Given that we include metropolitan and birth country dummies in the equations, identification requires that there are no additional interaction effects. The differencing approach we outlined above eliminates these effects but to explore for the presence of direct metropolitan area and birth country effects we first test for the joint presence of these effects in the OLS specifications. Given the large number of observations one would expect this hypothesis to be easily rejected but for the twenty specifications the highest $\mathrm{F}$ value was 8.94 while the lowest was $2.97 .^{8}$ Thus while there is some evidence of direct effects, it is not overwhelming. This suggest that the interactive effects are less likely to be an issue. Nevertheless we employed the differencing strategy as discussed above. Note that we use the data from the 1990 and 2000 censuses as only two cross sections are required and the greater the period between the cross sections employed the more likely that parameter variability, which invalidates the panel approach, arises. The estimates for the key variables are reported in Tables 6.3 and 6.4 .

The estimates in these tables are remarkably supportive of the network effects uncovered in Tables 6.1 and $6.2 .^{9}$ If we focus on the results for the top 5 occupations for all countries we see that the estimate of the network effect of 1.210 is almost exactly the mid point of the 2000 estimate of 1.171 and the 1990 estimate of 1.342 . The estimate for the non Mexican group of 1.283 also lies midway between the two cross sectional estimates of 1.135 and 1.559 . It is very important to note that there is nothing in the estimation procedures which generates such a result. It simply indicates that both procedures are eliminating the endogeneity. ${ }^{10}$

\footnotetext{
${ }^{8}$ The twenty specifications correspond to the 5 outcomes for each year for the samples with and without Mexicans.

${ }^{9}$ Whereas the cross sectional IV approach uses the distribution of the same occupations as instruments, in the pseudo panel we define the outcomes as the proportion in the most (1-5) popular occupations. Accordingly the occupations that appear in the most popular occupations may change across the two periods. Our approach nevertheless accounts for the interaction effects of interest. Note that all the regressors are defined in a consistent manner.

${ }^{10}$ The two estimation procedures are based on different moment conditions. They will give the same result if they both eliminate the endogeneity or if there is no endogeneity to eliminate.
} 


\section{Immigrant Networks and Wages}

The evidence above indicates that immigrant networks are leading to substantial growth of the shares of occupational location by immigrants. More notably, this growth appears to occur at a very localized level. We now focus on whether this phenomena has any implications for the earnings of recently arrived immigrants recalling that the conceptual model suggested such a relationship.

Previous research suggest that in some cases the use of networks results in higher wages. This has been established theoretically by Mortensen and Vishwanath (1994) and supported empirically by Beaman (2007), Bayer et al (2005), and Simon and Warner (1992). However, networks may not necessarily generate higher match quality (Elliot 1999, Ioannides and Datcher Loury 2004). Indeed, it may encourage high ability workers to accept relatively low ability jobs that are prevalent in their network (Bentolila et al 2006). We now examine the data to see if any patterns emerge. We reestimate equation (5) but employ two alternative dependent variables. First we use the log of the hourly wage as this captures the individual's wage level in the chosen occupation. We then employ the log of the individual's weekly wage as this may incorporate additional network effects.

For both dependent variables we use the same conditioning variables as in the occupational choice model to capture the individual's background characteristics. However, for the network effect we employ two different approaches. First, we use dummy variables to indicate the selection of the individual into the most commonly chosen occupation(s) of his/her ethnic group. Second, we use the occupational share of the "established immigrants" for the choice of that individual interacted with the dummy variable indicating the occupation(s) is the most commonly chosen. The first estimate is the average effect from locating in the most popular occupation(s). The second estimate indicates the marginal return for increasing the share of the most commonly chosen occupation. The estimates for the key coefficients of interest for both specifications and for the samples with and without the Mexican workers are reported in Tables 7.1 to 7.4. These tables include the results for the most popular and the five most popular occupations. The full set of results for these and the additional outcome variables are reported in appendix Tables A7.1b to A7.4b. Once again the evidence in favor of endogeneity is very persuasive and we focus only on the IV estimates noting that we employ the same instruments as in the previous section. However, the corresponding OLS estimates are presented in Appendix Tables A7.1a to A7.4a for comparison 
and there is relatively little difference in the estimates of the network effects. Also note that in this case the dependent variables does not change but the key regressors do as we include additional outcomes.

First consider the sample of all immigrants and where the dependent variable is the log of the hourly wage. The results when the network effect is captured by a dummy variable are presented in Table 7.1 while those captured by the dummy interacted with $Y_{j m o t}^{e s t a b}$ are reported in Table 7.2. We first focus on the former.

The results for 1990 indicate that, location in the most commonly chosen occupation of that individual's ethnic group increases the individual's wage by a sizeable 9.5 percent. As we expand the definition of the most popular occupations there is a slight increase in the effect. Interestingly, we also see statistically significant effects from the ethnic composition of the occupation. For example, being located in an occupation with more native born workers increases the wage in a non trivial way. In contrast, there appears to be no effect from the size of the occupation.

Table 7.1 also presents the results for the year 2000 and they are very similar to those for 1990 although there is a reduction with respect to the impact of the network effect. The premium for the most commonly chosen outcome is around 8 percent and for the 2000 data the effect is invariant to the number of outcomes considered here. This is consistent with our earlier results for the occupational choice model which suggested the network effects are operating in a range of occupations for each ethnic group. Another remarkable feature is the sizeable increase in the variable which captures the presence of native born. In contrast there continues to be no "occupation share" effect.

Table 7.2 replaces the dummy variable capturing the network effects with the occupational share of the group in question interacted with the indicator function used in Table 7.1. This allows us to infer the increase in wage which results from an increase in the size of the occupation share. For the 1990 and 2000 data there are substantial effects. The point estimate for 1990 is .43 recalling that the mean for this variable is .015. This indicates that as the occupation share increases by over 4.3 percent for a 10 percentage point increase in the share. The corresponding estimate for the 2000 data is 4.2 percent. It should be noted that the large effect using the indicator function as the network effect represents an average effect. Table 5.1 reveals the occupational shares for some ethnic groups in certain regions may be as high as 40 percent. Using the estimate for the single outcome category for the 2000 census means that the wage is almost 20 percent higher than 
someone who has no-one else from his/her country in his/her occupation.

Now focus on the corresponding estimates for the sample excluding Mexican workers from the LHS. The outcomes for the measures using the dummy variables are presented in Table 7.3 and the estimates with the interacted continuous outcomes are in Table 7.4. First consider Table 7.3. For both 1990 and 2000 there again is strong evidence of network effects. For 1990 the single occupation category effect is 10.9 percent and this only decreases to 10.1 percent as we include the next four occupations. For the 2000 data, however, the effect has increased to over 15 percent for the most populated outcome although this decreases to 11 percent as we include the next four occupations. The coefficients for the composition effects are similar to those for Table 7.2 although there are changes in magnitude.

Table 7.4 replaces the dummy variable with the fraction comprising that occupational group. For 1990, however, the estimates of the network effect for this sample have doubled in comparison to the sample including the Mexican workers. The estimates for 2000 however show a larger effect with the coefficient for the unique occupation now 1.185. The coefficients for the native born variables are similar to that for the entire sample. However, the coefficients on the size of the occupation are now much larger. Although we do not focus on the remaining conditioning variables they have the expected signs in Tables 7.1 to 7.4 .

The increase in the network effect for the sample of non Mexicans indicates that the network effect for the Mexican workers is somewhat weaker. To establish whether there is any network effect for Mexican workers we re-estimate the wage equations over the sample of Mexicans. We focus here on the estimates for our second measure of the network effect. For the 2000 Censuses there are no statistically significant network effects. For the 1990 Census the estimate of the coefficient on the network variable ranges from .338 to .383 , as one goes from the top occupation to the top five, and they are statistically significant. These estimates are notably lower than those in Table 7.4. The marginal effect of networks are thus substantially lower for Mexican workers in 1990 and non-existent in the other years. The results are generally consistent with the conceptual model which suggests the individual's wage increases when employed in the network.

The evidence thus suggest that for non-Mexican workers there is a sizeable pay increase to locating in the occupation in which your fellow countrymen are already located. One might expect that this effect underestimates the total impact on earnings as it does not capture the probability 
of finding work nor does it reflect the number of hours the person is able to work. Although the conceptual model does not address this issue, to incorporate this latter effect we re-estimate the earnings equation but use the log of the weekly wage as the dependent variable. We use the same samples and specifications as for Tables 7.1 to 7.4 .

Table 7.5 reports the estimates using the sample of all workers and the indicator function measure of networks. For both 1990 and 2000 there are substantial and statistically significant effects. In fact, for 1990 and 2000 the results indicate that the individual's weekly wage increases by 14 and 12 percent respectively if they locate in the most commonly chosen occupation. Increasing the network effect to include more occupations has no effect on the 2000 sample and slightly increases the estimate in 1990.

Table 7.6 reports the estimates for the alternative network measures. The results are substantially the same as those for the indicator measures and reflect large effects. For example, a 10 percent increase in the size of the network results in a 6 percent increase in weekly wages for both 1990 and 2000. Table 5.2 indicates that a share of 10 percent, which measures the size of the network, is not unusual.

Tables 7.7 and 7.8 report the corresponding estimates for the weekly wage equation for the sample not including the Mexican workers on the LHS. The indicator function measure of the network effect indicates an increase of over 20 percent for membership in the most populated group in 1990 and almost 25 percent in 2000. The conclusions from using the alternative measure, featured

in Table 7.8, reveal a drastic increase in the marginal effects from increasing the immigrants' share in contrast to Table 7.6. For example, for both 1990 and 2000 we see that increasing the immigrants' size of the occupation by 10 percentage points increases the weekly wage by almost 20 percent. Note that we do employ the pseudo panel approach here as the coefficients are not as readily interpretable as in the previous section.

\section{Discussion}

The empirical evidence reported in the previous sections appears to be important from a number of perspectives. To consider the implications of this evidence it is useful to consider the major results, and their implications, in isolation. Accordingly, we first focus on the role of immigrant 
networks in occupational choice. The discussion which follows is consistent with the conceptual model presented above.

The anecdotal evidence in Section 5 uncovered patterns of "immigrant clustering" in specific occupations. This clustering appears to be increasing in intensity over the last twenty years. More importantly, the clustering appeared to take place at the regional level and varied by ethnic group. Moreover, given that there is regional variation in the allocation of country specific immigrants to occupations the observed allocation did not appear to be the result of country specific skills. This conclusion also seems to be supported by the observation that many of the occupations which display the highest degree of clustering are not particularly skill intensive. The evidence in Section 6 clearly supports that this observed clustering is the result of immigrant networks. Namely, the most recently arrived immigrants appear to be following their countrymen who are located in the same local labor market into the same occupations. While we find very strong evidence of this effect for all immigrants we find that the effect is even stronger if we exclude Mexican workers.

Before proceeding to the economic implications of this result consider the mechanisms it might be capturing. The occupational allocation is likely to be reflecting both supply and demand factors. From the supply perspective a number of influences may be operating. For example, when individuals arrive in the US they will generally be unemployed and actively seeking job opportunities. If such individuals have contact with people from their home country who are employed it is likely that they will have greater information about opportunities in those sectors in which they are employed. While this may take the form of referrals or contacts it may be as simple as being alerted to vacancies in that occupation.

Related to these supply influences is the role of the offered wage. The evidence in Section 6 indicates that there is a large premium for recent immigrants who locate in the occupations in their local labor market which have the highest proportion of their countrymen. While we delay a discussion of what this premium captures to below, it is clear that these potentially large premia may influence the occupational location decision. That is, recent immigrants may be locating in these occupations due to the higher wage. This is an interesting research question although it is beyond the scope of this paper.

While supply influences may contribute to, and may even dominate, the network effect it is likely that demand influences are also relevant. For example, employers who are satisfied with 
workers from particular countries may be, due to positive experiences or prejudices, more likely to hire workers with the same background. Potential employers may also make such hiring decisions with the expectation that the workers from the same background are more likely to monitor each other, due to the fact that one worker's poor performance may reflect on that of the group, and this will reduce absenteeism or delinquent work behavior. This type of "risk sharing" behavior and its implication for occupational choice is a research area worth pursuing although we do not have the appropriate data at our disposal.

While our empirical evidence is not consistent with an argument based on the allocation of immigrant labor across occupations on the basis of skills it is useful to further address this possibility with an alternative data set which provides information on the individual's occupation prior to their arrival in the US. It is also possible that many of our results are due to the inclusion of illegal immigrants who may be more reliant on networks due to their restricted ability to pursue employment opportunities. The New Immigrant Survey (NIS) data set is composed of legal permanent residents residing in the top 85 US metropolitan areas ranked in terms of population of new legal immigrants. The first wave of questionnaires was conducted in 2003 and includes detailed immigrant employment histories. The NIS data set, however, is relatively small and provides usable information for about 5,000 immigrants. Furthermore, the country of birth is reported only for popular countries, while those from the remaining countries are reported by continent. Similarly, those immigrants who come from popular states have their state of residence reported while those from less popular states have their region of residence reported. The actual metropolitan areas are not reported.

We combined the NIS data with the census data and re-estimated the occupational choice model for two samples from the data. ${ }^{11}$ First, we included all the data which were usable. Second, we included only observations which reported a change in occupation from their last occupation in their home country. For both samples the coefficient for the network variable was positive and statistically significant in 12 of the 20 specifications. ${ }^{12}$ Moreover, the coefficient was roughly of the same magnitude for both samples. This suggests that the network effects are equally strong for those

\footnotetext{
${ }^{11}$ In estimating the model with the NIS data we included the same regressors as those used in our analysis of the Census data. In addition we included variables reflecting visa type, foreign and US schooling, and foreign and US work experience.

${ }^{12}$ These correspond to the 1 to 5 most popular occupations for the two samples, reporting changing and not changing occupations, for the samples including and excluding Mexicans.
} 
remaining in the same occupation as those changing occupations. This provides additional support for our conclusion that comparative advantage is not the driving force in the occupation allocation of immigrants. Note, in comparison to our results based on the census data the coefficients on the network variables were smaller in magnitude but continued to suggest reasonably large effects. ${ }^{13}$

While the evidence on the occupational clustering of immigrant strongly supports the operation of networks, perhaps the most striking empirical result in the paper is the effect of these networks on the individual's hourly and weekly wage. Once again it is valuable to consider the possible underlying factors driving this result. While the model in Section 3 suggests the observed accepted wage may be higher due to the faster arrival rate of offers in the network sector, there are other potential influences on the wages.

One explanation of the wage premium is that it reflects the market power of the network. That is, if the group comprises a sufficiently large share of the occupation this may provide the group's members with increased bargaining power when negotiating with employers. This is unlikely to be true, however, in labor markets where there are other sources of substitutable labor readily available.

Another possible reason for the premium is that if the employers are hiring from a specific pool of immigrant labor and are relying on internal references they may be able to reduce their hiring and search costs. If they are able to do so they may decide to pass some of this reduction on to the new employees thereby generating a wage premium.

Immigrant workers may find that they have difficulties in communicating with the fellow workers when they are located in a workplace which is not populated by others who speak the same language. One implication of such difficulties would be a reduction in their, and perhaps those working with them, productivity. For this reason workers who locate in occupations with those from their own country might experience higher wages. It is also possible that recent immigrants who locate in these types of occupations might encounter individuals from their home country who are in positions of authority in the workplace and this may, for a number of reasons, increase the wage they receive.

Understanding the nature of these network effects and the mechanisms by which they generate wage increases are important areas of research. Equally important is understanding what may be

\footnotetext{
${ }^{13}$ For immigrants from all countries the estimates of the network coefficient ranged from .33 to.42 depending on which occupations are included in the most popular category. For the sample excluding Mexican workers the estimates range from .43 to .94 .
} 
the product of occupational clustering. For example, it is possible that if clustering continued in this manner for several decades many occupations in local areas would be dominated by ethnic groups. Understanding the economic implications of such an outcome is an interesting exercise.

One final observation which merits discussion is the apparent difference in the results for the samples including and excluding the Mexican observations. Clearly the network effects, both for the occupational choice and wage equations, are weaker for Mexican workers. It is not clear what is driving either of these results as Mexicans have a larger share of the labor market than any other immigrant group. Identifying the factors underlying the differences in the network effects for Mexicans and the other ethnic groups is an area worth investigating in future research.

\section{Conclusion}

This paper documents the occupational allocation of immigrants in the United States. We pay particular attention to the location decisions of immigrants who have recently arrived in the United States. An examination of 1980, 1990 and 2000 Census data reveals that the occupational share of certain ethnic groups has grown drastically in particular labor markets over the period 1980 to 2000. Moreover, the pattern of growth seems to be consistent with the presence of network effects. That is, recently arrived immigrants are locating in the same occupations as their countrymen from previous waves of immigration. The data also does not appear to suggest the observed allocation is the result of sorting on the basis of comparative advantage.

In addition to examining for the presence of network effects in occupational sorting by immigrants we consider whether these networks have implications for the earnings of recently arrived immigrants. The evidence suggests that the hourly wage premium paid to an individual locating in the "most popular" occupation of his/her countrymen is of the order of 8 percent in 2000. This estimate increases to 15 percent however if we focus only on non-Mexican immigrants. There is also a substantial increase in the weekly earnings levels of both groups. 


\section{References}

Bayer, P. S. Ross, and G. Topa (2005). "Place of Work and Place of Residence: Informal Hiring Networks and Labor Market Outcomes," NBER Working Papers 11019, National Bureau of Economic Research.

Beaman, L. (2007). "Social Networks and the Dynamics of Labor Market Outcomes: Evidence from Refugees Resettled in the US," Yale University working paper.

Bentolila, S., C. Michelacci, and J. Suarez (2004). "Social Contacts and Occupational Choice." CEMFI Working Paper 0406.

Blau, D. (1992). "An Empirical Analysis of Employed and Unemployed Job Search Behavior," Industrial Labor Relations Review, Vol. 45, No.4, pp. 738-752.

Blau, D., and P.Robins (1990). "Job Search Outcomes for the Employed and Unemployed," The Journal of Political Economy, Vol. 98, No. 3., pp. 637-655.

Borjas, G. (1999). "The Economic Analysis of Immigration," in Handbook of Labor Economics, Volume 3A, edited by O. Ashenfelter and D.Card, North-Holland, pp. 1697-1760.

Borjas, G. (1985). "Assimilation, Changes in Cohort Quality, and the Earnings of Immigrants," Journal of Labor Economics, Vol.3, No. 4, pp. 463-489.

Borjas, G. (1999). Heaven's Door, Princeton University Press, Princeton, NJ.

Borjas, G. (2001). "Does Immigration Grease the Wheels of the Labor Market?" Brookings Papers on Economic Activity, Vol. 2001, No. 2, pp. 69-119.

Bortnick, S., and M. Ports (1992) "Job Search Methods and Results: Tracking the Unemployed." Monthly Labor Review, Vol. 115, No. 12, pp.29-35.

Bradshaw, T. (1973). "Jobseeking Methods Used by Unemployed Workers," Monthly Labor Review, Vol. 96, No. 2, pp. 35-40.

Calvo-Armengol, A., (2004). "Job Contact Networks," Journal of Economic Theory, Vol. 115, No. 1, pp. 191-206.

Calvo-Armengol, A., and M. Jackson, (2007). "Networks in Labor Markets: Wage and Employment Dynamics and Inequality," Journal of Economic Theory, Vol. 132, No. 1, pp.507-517.

Edin, P., P.Fredriksson, and P.Aslund, (2003). "Ethnic Enclaves and the Economic Success of Immigrants-Evidence From a Natural Experiment," Quarterly Journal of Economics, Vol. 118, No. 1, pp. 329-357. 
Elliot, J. (1999). "Social Isolation and labor market isolation: network and neighborhood Effects on Less Educated Urban Workers," Sociological Quarterly. Vol. 40, No. 2, pp.199-216.

Ioannides, Y., and L. Datcher Loury (2004). "Job Information Networks, Neighborhood Effects, and Inequality," Journal of Economic Literature, Vol. 42 pp.1056-1093.

Laschever, R. (2007). "The Doughboys Network: Social Interactions and Labor Market Outcomes of World War I Veterans," University of Illinois at Urbana-Champaign working paper.

Logan, J., W. Zhang, and R. Alba (2002). "Immigrant Enclaves and Ethnic Communities in New York and Los Angeles," American Sociological Review, Vol. 67, No. 2., pp. 299-322.

Model, S. (1993). "The Ethnic Niche and the Structure of Opportunity: Immigrants and Minorities in New York City," The Underclass Debate. M.B. Katz. Princeton, N.J.: Princeton University Press.

Montgomery, J. (1991). "Social Networks and Labor Market Outcomes: Towards an Economic Analysis," American Economic Review. Vol. 81, No. 5, pp 1408-18.

Mortensen, D., and T. Vishwanath (1994). "Personal Contacts and Earnings: It Is Who You Know," Labor Economics Vol 1 No. 2 pp. 187-201.

Munshi, K., and N. Wilson (2007). "Identity and Occupational Choice in the American Midwest," Brown University working paper.

Munshi, K. (2003). "Networks in the Modern Economy: Mexican Migrants in the US Labor Market," The Quarterly Journal of Economics, pp 549-597.

Parks, V. (2005), The Geography of Immigrant Labor Markets: Space Networks and Gender. LFB Scholarly Publishing LLC, New York, NY.

Roy, A. D., (1951). "Some Thoughts on the Distribution of Earnings" Oxford Economic Papers, New Series, Vol. 3, No. 2, pp. 135-146.

Simon, C. and J. Warner (1992)., "Matchmaker, Matchmaker: The Effect of Old Boy Networks on Job Match Quality, Earnings and Tenure," Journal of Labor Economics. Vol. 10, No. 3, pp. 306-30.

Topa, G. (2001). "Social Interactions, Local Spillovers and Unemployment," The Review of Economic Studies, Vol. 68, No. 2., pp. 261-295.

Waldinger, R. (1996) Still the Promised City? Boston University Press, Boston MA.

Waldinger, R. (1994). "The Making of an Immigrant Niche," International Migration Review, 
Vol. 28, No. 1, pp. 3-30. 


\section{Tables and Figures}

Table 5.1: Occupation Concentration by Birth Country, Conditional on Being in the Top 5 Most Popular Occupation in 2000

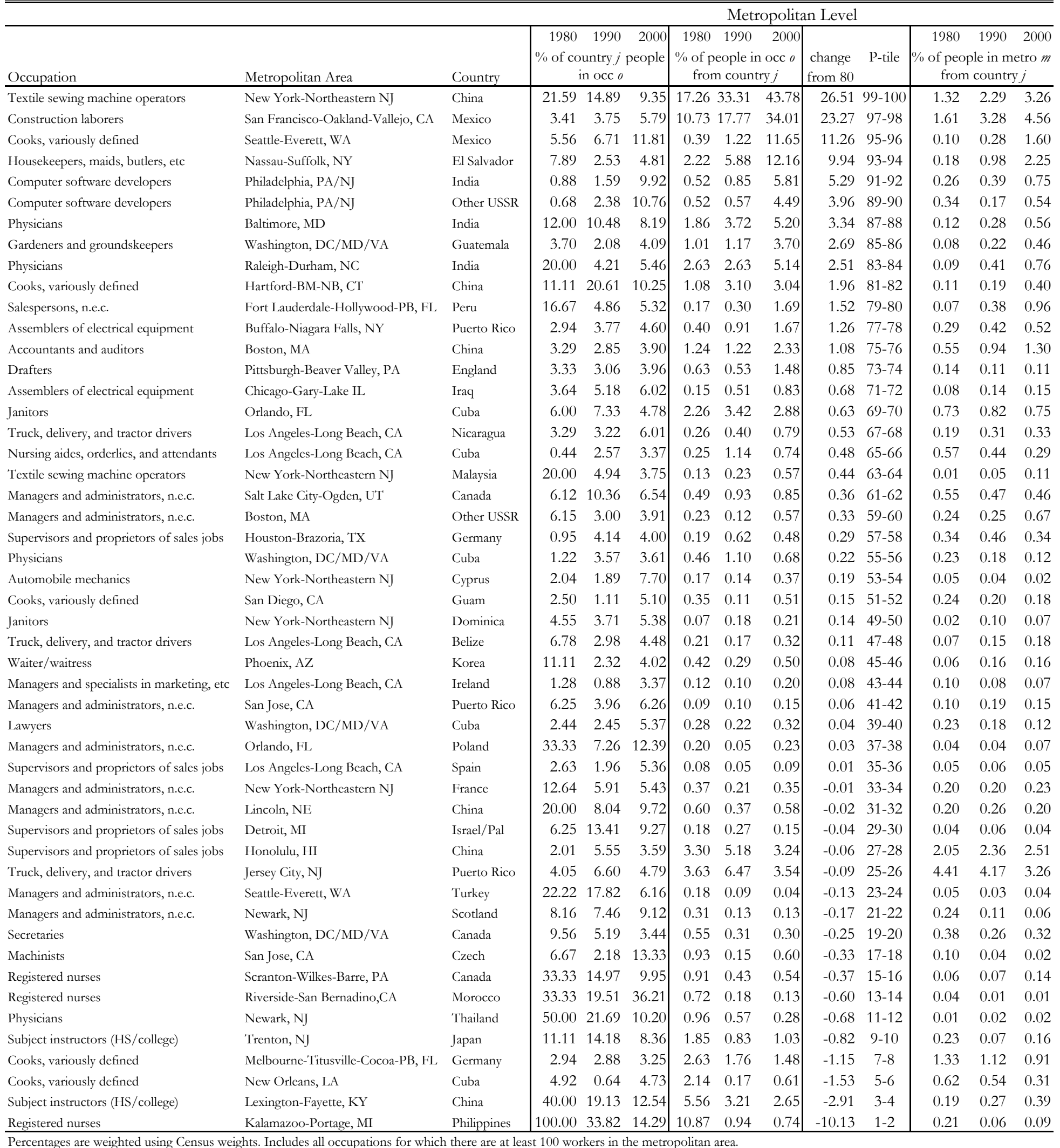


Table 5.2: Occupation Concentration by Birth Country: Highest Growth 1980--2000

\begin{tabular}{|c|c|c|c|c|c|c|c|c|c|c|c|c|}
\hline \multirow[b]{2}{*}{ Occupation } & \multirow[b]{2}{*}{ Metropolitan Area } & \multirow[b]{2}{*}{ Country } & \multicolumn{7}{|c|}{ Metropolitan Level } & \multicolumn{3}{|c|}{ National Level } \\
\hline & & & $\begin{array}{r}1980 \\
\% \text { of pec } \\
\text { fror }\end{array}$ & $\begin{array}{r}1990 \\
\text { ple in } m \\
\text { a countr }\end{array}$ & \begin{tabular}{|l|}
2000 \\
etro $m$ \\
$j$
\end{tabular} & $\begin{array}{r}1980 \\
\% \text { of } \mathrm{p} \\
\text { fron }\end{array}$ & $\begin{array}{r}1990 \\
\text { cople in } \\
\text { countr }\end{array}$ & $\begin{array}{l}2000 \\
\operatorname{ccc} 0 \\
j\end{array}$ & $\begin{array}{c}\text { change } \\
\text { from } 80 \\
\end{array}$ & $\begin{array}{r}1980 \\
\% \text { of } \mathrm{p} \\
\text { fror } \\
\end{array}$ & $\begin{array}{r}1990 \\
\text { ople in }\end{array}$ & $\begin{array}{l}2000 \\
\operatorname{cc} 0 \\
j\end{array}$ \\
\hline Nursing aides, orderlies, and attendants & Fort Lauderdale-Hollywood-PB, FL & Jamaica & 0.76 & 2.31 & 4.91 & 5.94 & 21.95 & 38.82 & 32.88 & 1.49 & 2.03 & 2.62 \\
\hline Freight, stock, and materials handlers & San Francisco-Oakland-Vallejo, CA & Philippines & 2.64 & 5.12 & 5.28 & 1.79 & 3.32 & 30.26 & 28.48 & 0.18 & 0.48 & 1.82 \\
\hline Textile sewing machine operators & New York-Northeastern NJ & China & 1.32 & 2.29 & 3.26 & 17.26 & 33.31 & 43.78 & 26.51 & 4.82 & 7.45 & 8.87 \\
\hline Assemblers of electrical equipment & San Jose, CA & Vietnam & 0.58 & 2.8 & 4.91 & 3.41 & 16.47 & 29.77 & 26.35 & 0.65 & 1.93 & 3.65 \\
\hline Textile sewing machine operators & Seattle-Everett, WA & Vietnam & 0.15 & 0.59 & 1.29 & 1.89 & 3.58 & 27.10 & 25.21 & 0.49 & 1.52 & 4.62 \\
\hline Mail carriers for postal service & San Jose, CA & Philippines & 2.03 & 3.57 & 4.09 & 6.90 & 22.43 & 31.14 & 24.25 & 0.47 & 1.47 & 2.09 \\
\hline Textile sewing machine operators & San Francisco-Oakland-Vallejo, CA & China & 2.82 & 5.56 & 6.42 & 52.60 & 70.34 & 76.66 & 24.06 & 4.82 & 7.45 & 8.87 \\
\hline Hairdressers and cosmetologists & Houston-Brazoria, TX & Vietnam & 0.31 & 0.91 & 1.52 & 0.68 & 6.21 & 24.18 & 23.50 & 0.05 & 1.41 & 6.17 \\
\hline Licensed practical nurses & Fort Lauderdale-Hollywood-PB, FL & Jamaica & 0.76 & 2.31 & 4.91 & 3.51 & 6.80 & 26.68 & 23.17 & 0.35 & 0.68 & 1.49 \\
\hline Misc food prep workers & Fort Lauderdale-Hollywood-PB, FL & Haiti & 0.26 & 2.19 & 3.79 & 4.00 & 23.52 & 26.56 & 22.56 & 0.22 & 0.58 & 0.53 \\
\hline Textile sewing machine operators & Providence-Fall River-Pawtuckett, MA & Portugal & 3.37 & 2.36 & 4.25 & 17.50 & 13.21 & 39.02 & 21.52 & 2.21 & 1.97 & 1.24 \\
\hline Nursing aides, orderlies, and attendants & San Jose, CA & Philippines & 2.03 & 3.57 & 4.09 & 2.19 & 13.91 & 23.62 & 21.43 & 0.80 & 1.68 & 2.38 \\
\hline Nursing aides, orderlies, and attendants & San Francisco-Oakland-Vallejo, CA & Philippines & 2.64 & 5.12 & 5.28 & 5.84 & 15.82 & 26.82 & 20.98 & 0.80 & 1.68 & 2.38 \\
\hline Misc food prep workers & Washington, DC/MD/VA & El Salvador & 0.13 & 1.24 & 2.33 & 1.06 & 20.18 & 21.62 & 20.56 & 0.28 & 1.62 & 1.77 \\
\hline Painters, construction and maintenance & Washington, $\mathrm{DC} / \mathrm{MD} / \mathrm{VA}$ & El Salvador & 0.13 & 1.24 & 2.33 & 1.32 & 10.93 & 21.15 & 19.83 & 0.24 & 1.48 & 2.14 \\
\hline Packers and packagers by hand & Nassau-Suffolk, NY & El Salvador & 0.18 & 0.98 & 2.25 & 1.38 & 7.35 & 20.93 & 19.56 & 0.30 & 1.10 & 2.15 \\
\hline Nursing aides, orderlies, and attendants & West Palm Beach-Boca Raton-DB, FL & Jamaica & 0.36 & 1.11 & 1.94 & 1.45 & 9.85 & 20.56 & 19.11 & 1.49 & 2.03 & 2.62 \\
\hline Pressing machine operators (clothing) & New York-Northeastern NJ & China & 1.32 & 2.29 & 3.26 & 12.12 & 25.29 & 30.90 & 18.78 & 2.43 & 2.19 & 2.82 \\
\hline Housekeepers, maids, butlers, stewards, etc & Washington, $\mathrm{DC} / \mathrm{MD} / \mathrm{VA}$ & El Salvador & 0.13 & 1.24 & 2.33 & 4.07 & 14.86 & 22.43 & 18.36 & 0.85 & 2.25 & 3.74 \\
\hline Construction laborers & Washington, $\mathrm{DC} / \mathrm{MD} / \mathrm{VA}$ & El Salvador & 0.13 & 1.24 & 2.33 & 1.44 & 14.81 & 19.50 & 18.06 & 0.16 & 1.09 & 1.60 \\
\hline Misc food prep workers & Nassau-Suffolk, NY & El Salvador & 0.18 & 0.98 & 2.25 & 1.53 & 9.09 & 19.44 & 17.91 & 0.28 & 1.62 & 1.77 \\
\hline Machine operators, n.e.c. & San Francisco-Oakland-Vallejo, CA & China & 2.82 & 5.56 & 6.42 & 2.67 & 8.68 & 20.34 & 17.67 & 0.16 & 0.31 & 0.87 \\
\hline Machine operators, n.e.c. & Nassau-Suffolk, NY & El Salvador & 0.18 & 0.98 & 2.25 & 2.47 & 12.52 & 19.48 & 17.01 & 0.27 & 0.92 & 1.02 \\
\hline Printing machine operators, n.e.c. & San Francisco-Oakland-Vallejo, CA & China & 2.82 & 5.56 & 6.42 & 3.42 & 8.26 & 20.39 & 16.97 & 0.19 & 0.29 & 0.75 \\
\hline Gardeners and groundskeepers & Nassau-Suffolk, NY & El Salvador & 0.18 & 0.98 & 2.25 & 0.75 & 6.60 & 17.52 & 16.78 & 0.17 & 1.15 & 1.65 \\
\hline Postal clerks, excluding mail carriers & San Francisco-Oakland-Vallejo, CA & China & 2.82 & 5.56 & 6.42 & 3.05 & 11.78 & 19.40 & 16.35 & 0.21 & 1.22 & 2.04 \\
\hline Gardeners and groundskeepers & Honolulu, HI & Philippines & 7.42 & 8.73 & 10.6 & 20.41 & 29.89 & 36.70 & 16.29 & 0.46 & 0.39 & 0.34 \\
\hline Janitors & Honolulu, HI & Philippines & 7.42 & 8.73 & 10.6 & 23.63 & 26.58 & 39.88 & 16.25 & 0.52 & 0.80 & 0.96 \\
\hline Nursing aides, orderlies, and attendants & Vallejo-Fairfield-Napa, CA & Philippines & 1.65 & 2.96 & 4.16 & 8.89 & 11.00 & 24.90 & 16.01 & 0.80 & 1.68 & 2.38 \\
\hline Mail carriers for postal service & San Francisco-Oakland-Vallejo, CA & Philippines & 2.64 & 5.12 & 5.28 & 4.17 & 13.20 & 20.15 & 15.98 & 0.47 & 1.47 & 2.09 \\
\hline Clinical laboratory technologies and tech & San Diego, CA & Philippines & 1.82 & 3.46 & 3.93 & 2.94 & 17.38 & 18.85 & 15.91 & 2.76 & 3.77 & 4.15 \\
\hline Drafters & San Jose, CA & Vietnam & 0.58 & 2.8 & 4.91 & 1.00 & 5.50 & 16.80 & 15.80 & 0.40 & 0.56 & 1.19 \\
\hline Textile sewing machine operators & New Bedford, MA & Portugal & 12.23 & 17.82 & 10.22 & 55.43 & 69.42 & 71.15 & 15.71 & 2.21 & 1.97 & 1.24 \\
\hline Clinical laboratory technologies and tech & San Francisco-Oakland-Vallejo, CA & Philippines & 2.64 & 5.12 & 5.28 & 5.95 & 16.71 & 21.57 & 15.62 & 2.76 & 3.77 & 4.15 \\
\hline Machinists & San Jose, CA & Vietnam & 0.58 & 2.8 & 4.91 & 0.93 & 3.79 & 16.18 & 15.25 & 0.24 & 0.91 & 1.81 \\
\hline Cooks, variously defined & Washington, DC/MD/VA & El Salvador & 0.13 & 1.24 & 2.33 & 0.23 & 9.79 & 15.40 & 15.17 & 0.15 & 1.05 & 1.42 \\
\hline etcand news vendors & San Francisco-Oakland-Vallejo, CA & Philippines & 2.64 & 5.12 & 5.28 & 0.89 & 4.86 & 16.01 & 15.11 & 0.29 & 0.30 & 0.39 \\
\hline Slicing and cutting machine operators & New York-Northeastern NJ & Ecuador & 0.57 & 0.88 & 1.4 & 2.22 & 3.14 & 17.31 & 15.09 & 0.22 & 0.31 & 0.61 \\
\hline Janitors & Washington, DC/MD/VA & El Salvador & 0.13 & 1.24 & 2.33 & 0.58 & 8.46 & 15.66 & 15.08 & 0.16 & 1.26 & 1.60 \\
\hline Assemblers of electrical equipment & San Francisco-Oakland-Vallejo, CA & China & 2.82 & 5.56 & 6.42 & 2.75 & 10.17 & 17.58 & 14.83 & 0.22 & 0.48 & 0.64 \\
\hline Nursing aides, orderlies, and attendants & Stockton, CA & Philippines & 1.7 & 2.28 & 2.88 & 2.33 & 9.59 & 16.94 & 14.62 & 0.80 & 1.68 & 2.38 \\
\hline Farm workers & West Palm Beach-Boca Raton-DB, FL & Haiti & 0.1 & 1.96 & 3.49 & 3.41 & 10.33 & 18.02 & 14.61 & 0.05 & 0.40 & 0.39 \\
\hline Housekeepers, maids, butlers, stewards, etc & San Francisco-Oakland-Vallejo, CA & El Salvador & 0.42 & 1.74 & 1.7 & 4.00 & 9.60 & 18.41 & 14.41 & 0.85 & 2.25 & 3.74 \\
\hline Housekeepers, maids, butlers, stewards, etc & Honolulu, HI & Philippines & 7.42 & 8.73 & 10.6 & 40.70 & 49.83 & 54.96 & 14.26 & 1.08 & 2.16 & 1.80 \\
\hline Postal clerks, excluding mail carriers & San Diego, CA & Philippines & 1.82 & 3.46 & 3.93 & 6.82 & 22.68 & 20.96 & 14.14 & 0.87 & 2.47 & 2.58 \\
\hline Computer software developers & Trenton, NJ & India & 0.35 & 0.75 & 1.65 & 4.76 & 3.54 & 18.83 & 14.07 & 0.58 & 1.05 & 7.05 \\
\hline Janitors & Fort Lauderdale-Hollywood-PB, FL & Haiti & 0.26 & 2.19 & 3.79 & 0.69 & 9.12 & 14.61 & 13.92 & 0.12 & 0.42 & 0.44 \\
\hline Cooks, variously defined & Fort Lauderdale-Hollywood-PB, FL & Haiti & 0.26 & 2.19 & 3.79 & 0.88 & 8.41 & 14.75 & 13.87 & 0.05 & 0.34 & 0.42 \\
\hline Computer software developers & Newark, NJ & India & 0.42 & 1.01 & 1.57 & 1.80 & 3.17 & 15.56 & 13.76 & 0.58 & 1.05 & 7.05 \\
\hline Packers and packagers by hand & Bergen-Passaic, NJ & Dom Rep. & 0.99 & 1.55 & 2.66 & 4.55 & 13.63 & 18.30 & 13.76 & 0.58 & 1.01 & 1.97 \\
\hline
\end{tabular}

Packers and packagers by hand

Bergen-Passaic, NJ

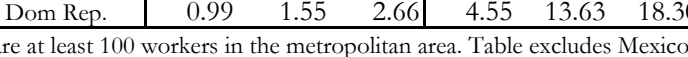




\begin{tabular}{|c|c|c|c|c|c|c|c|c|c|c|c|c|c|}
\hline \multirow[b]{2}{*}{ Country of Origin } & \multicolumn{3}{|c|}{$\begin{array}{c}\text { No. of Unique Top } \\
\text { Occupations Across } \\
\text { Metro-Areas }\end{array}$} & \multicolumn{3}{|c|}{$\begin{array}{l}\text { No. of Popular } \\
\text { Occupations / No. } \\
\text { of Metro-Areas * }\end{array}$} & \multirow[b]{2}{*}{ Country of Origin } & \multicolumn{3}{|c|}{$\begin{array}{c}\text { No. of Unique Top } \\
\text { Occupations Across } \\
\text { Metro-Areas }\end{array}$} & \multicolumn{3}{|c|}{$\begin{array}{c}\text { No. of Popular } \\
\text { Occupations / No. } \\
\text { of Metro-Areas } *\end{array}$} \\
\hline & 1980 & 1990 & 2000 & 1980 & 1990 & 2000 & & 1980 & 1990 & 2000 & 1980 & 1990 & 2000 \\
\hline American Samoa & & & 1 & & & 1.00 & Jordan & & & 1 & & & 1.00 \\
\hline Guam & & 2 & 1 & & 1.00 & 1.00 & Lebanon & & 3 & 2 & & 0.60 & 0.40 \\
\hline Puerto Rico & 3 & 11 & 18 & 0.27 & 0.35 & 0.41 & Syria & & 1 & 1 & & 1.00 & 0.50 \\
\hline U.S. Virgin Islands & 1 & 1 & 1 & 1.00 & 1.00 & 1.00 & Turkey & & 2 & 2 & & 1.00 & 0.50 \\
\hline Other US Possessions & & 1 & & & 1.00 & & AFRICA & & & 4 & & & 0.80 \\
\hline Canada & 5 & 5 & 11 & 0.22 & 0.14 & 0.31 & Australia and NZ & & 1 & 4 & & 1.00 & 1.00 \\
\hline Atlantic Islands & & 1 & 2 & & 1.00 & 1.00 & Abroad (unknown) & 6 & 14 & & 0.75 & 0.47 & \\
\hline Mexico & 7 & 15 & 19 & 0.27 & 0.22 & 0.16 & Belize & & 1 & 1 & & 0.50 & 0.50 \\
\hline Cuba & 5 & 9 & 8 & 0.50 & 0.45 & 0.47 & Costa Rica & & 2 & 3 & & 1.00 & 0.75 \\
\hline West Indies & 1 & 1 & 1 & 1.00 & 1.00 & 1.00 & El Salvador & 3 & 8 & 8 & 1.00 & 0.47 & 0.36 \\
\hline England & 2 & 4 & 7 & 0.22 & 0.15 & 0.25 & Guatemala & 1 & 3 & 7 & 1.00 & 0.27 & 0.33 \\
\hline Scotland & 2 & 1 & 1 & 1.00 & 0.50 & 1.00 & Honduras & 1 & 4 & 8 & 1.00 & 1.00 & 0.62 \\
\hline United Kingdom, ns & & 1 & 5 & & 0.25 & 0.71 & Nicaragua & 2 & 6 & 6 & 1.00 & 0.86 & 0.75 \\
\hline Ireland & 4 & 6 & 5 & 1.00 & 0.75 & 0.71 & Panama & 1 & 3 & 3 & 1.00 & 0.75 & 1.00 \\
\hline France & 2 & 3 & 2 & 0.67 & 0.75 & 0.29 & Dominican Republic & 1 & 7 & 8 & 1.00 & 0.78 & 0.53 \\
\hline Netherlands & 1 & 1 & 1 & 1.00 & 1.00 & 1.00 & Haiti & 2 & 4 & 3 & 0.67 & 0.50 & 0.23 \\
\hline Switerland & & 1 & 1 & & 1.00 & 1.00 & Jamaica & 1 & 2 & 4 & 0.50 & 0.14 & 0.21 \\
\hline Albania & & & 2 & & & 1.00 & Antigua-Barbuda & & 1 & 1 & & 1.00 & 1.00 \\
\hline Greece & 2 & 2 & 4 & 0.67 & 0.25 & 0.40 & Bahamas & & 1 & 1 & & 1.00 & 1.00 \\
\hline Italy & 6 & 9 & 8 & 0.35 & 0.43 & 0.42 & Barbados & 1 & 1 & 1 & 1.00 & 1.00 & 1.00 \\
\hline Portugal & 3 & 5 & 6 & 0.50 & 0.38 & 0.60 & Dominica & & 1 & 1 & & 1.00 & 1.00 \\
\hline Spain & 1 & 4 & 3 & 1.00 & 1.00 & 1.00 & Grenada & & 1 & 1 & & 1.00 & 1.00 \\
\hline Austria & 1 & 1 & 1 & 1.00 & 1.00 & 1.00 & St. Kitts-Nevis & & & 1 & & & 1.00 \\
\hline Bulgaria & & & 1 & & & 1.00 & St. Lucia & & & 1 & & & 1.00 \\
\hline Czechoslovakia & 1 & 3 & 2 & 1.00 & 1.00 & 1.00 & St. Vincent & & 1 & 1 & & 1.00 & 1.00 \\
\hline Germany & 4 & 6 & 15 & 0.22 & 0.10 & 0.24 & Trinidad and Tobago & 1 & 2 & 3 & 1.00 & 0.50 & 0.43 \\
\hline Hungary & 1 & 1 & 1 & 0.50 & 0.50 & 0.50 & Argentina & 2 & 4 & 4 & 1.00 & 0.80 & 0.80 \\
\hline Poland & 4 & 4 & 9 & 0.67 & 0.33 & 0.69 & Bolivia & & 1 & 2 & & 1.00 & 1.00 \\
\hline Romania & 1 & 3 & 5 & 1.00 & 1.00 & 1.00 & Brazil & & 3 & 5 & & 0.60 & 0.45 \\
\hline Yugoslavia & 3 & 4 & 7 & 0.75 & 0.67 & 0.78 & Chile & & 1 & 2 & & 0.25 & 0.67 \\
\hline Lithuania & & 1 & 1 & & 1.00 & 1.00 & Colombia & 3 & 7 & 9 & 1.00 & 0.50 & 0.47 \\
\hline Other USSR/Russia & 2 & 5 & 7 & 0.50 & 0.71 & 0.30 & Ecuador & 3 & 6 & 7 & 1.00 & 0.67 & 0.70 \\
\hline Europe, ns & & & 1 & & & 1.00 & Guyana/British Guiana & 1 & 2 & 4 & 1.00 & 0.67 & 0.67 \\
\hline China & 4 & 8 & 9 & 0.33 & 0.31 & 0.23 & Peru & 3 & 7 & 10 & 1.00 & 0.70 & 0.71 \\
\hline Japan & 3 & 5 & 7 & 0.60 & 0.31 & 0.35 & Uruguay & & 1 & & & 1.00 & \\
\hline Korea & 3 & 6 & 10 & 0.60 & 0.30 & 0.37 & Venezuela & & 1 & 2 & & 1.00 & 1.00 \\
\hline Cambodia (Kampuchea) & & 3 & 3 & & 1.00 & 0.50 & South Korea & & 2 & 1 & & 0.40 & 0.20 \\
\hline Indonesia & 1 & 1 & 2 & 1.00 & 1.00 & 1.00 & Bangladesh & & 1 & 2 & & 1.00 & 1.00 \\
\hline Laos & & 1 & 2 & & 1.00 & 0.29 & Myanmar & & 2 & 3 & & 1.00 & 1.00 \\
\hline Malaysia & & & 2 & & & 1.00 & Pakistan & & 3 & 5 & & 0.75 & 0.56 \\
\hline Philippines & 8 & 9 & 7 & 0.67 & 0.24 & 0.16 & Egypt & 3 & 3 & 2 & 0.75 & 1.00 & 0.67 \\
\hline Thailand & 1 & 3 & 2 & 1.00 & 1.00 & 0.40 & Morocco & & & 2 & & & 1.00 \\
\hline Vietnam & 8 & 10 & 7 & 0.89 & 0.45 & 0.21 & Ghana & & 2 & 1 & & 1.00 & 0.50 \\
\hline Southeast Asia, ns & & & 1 & & & 0.50 & Liberia & & & 1 & & & 1.00 \\
\hline Afghanistan & & 1 & 2 & & 1.00 & 1.00 & Nigeria & & 3 & 3 & & 1.00 & 0.33 \\
\hline India & 3 & 6 & 7 & 0.50 & 0.29 & 0.16 & Sierra Leone & & & 1 & & & 1.00 \\
\hline Iran & 1 & 5 & 5 & 1.00 & 0.50 & 0.33 & Ethiopia & & 1 & 2 & & 1.00 & 0.67 \\
\hline Iraq & 1 & 3 & 2 & 1.00 & 1.00 & 0.50 & South Africa & & 1 & 2 & & 1.00 & 1.00 \\
\hline Israel/Palestine & 2 & 3 & 3 & 1.00 & 0.60 & 0.75 & Fiji & & & 3 & & 0.72 & 1.00 \\
\hline \multicolumn{8}{|c|}{ average (weighted by the country share of total immigrants) } & & & & 0.29 & 0.35 & 0.45 \\
\hline
\end{tabular}

$*$ This counts the number of occupations that are ranked 1 across metropolitan areas. In some metro area, some occupations are tied for 1 . Based on weighted data 

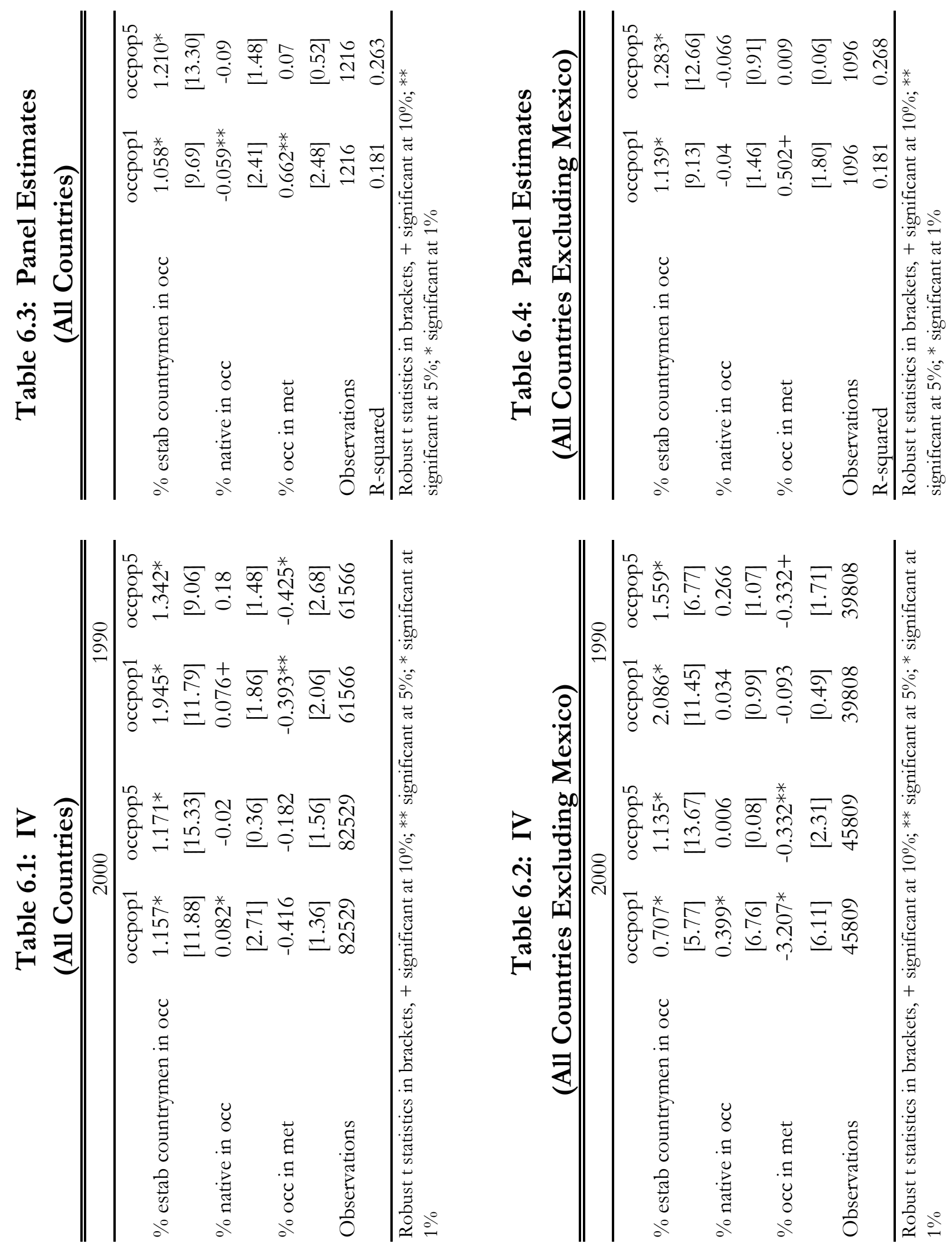

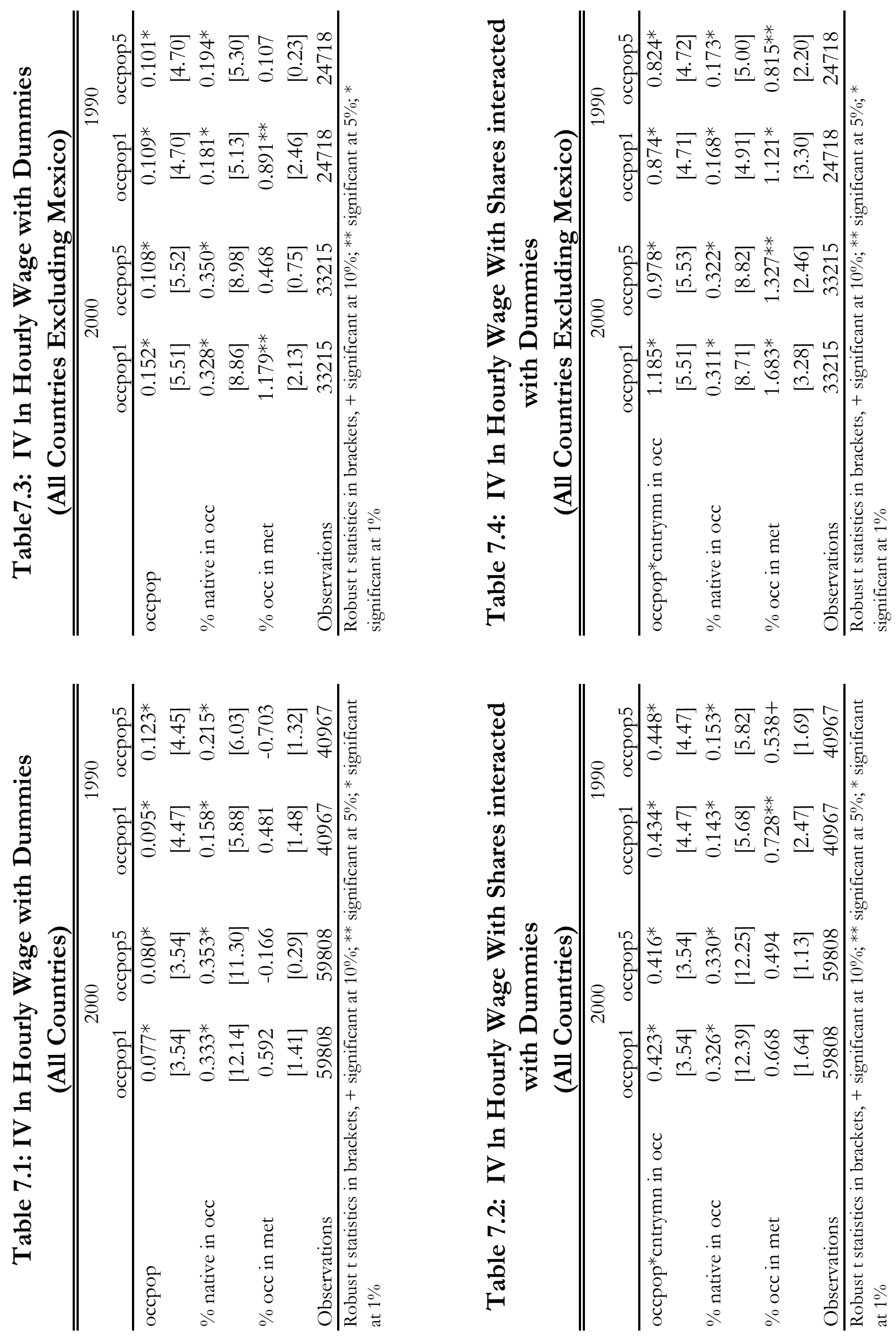

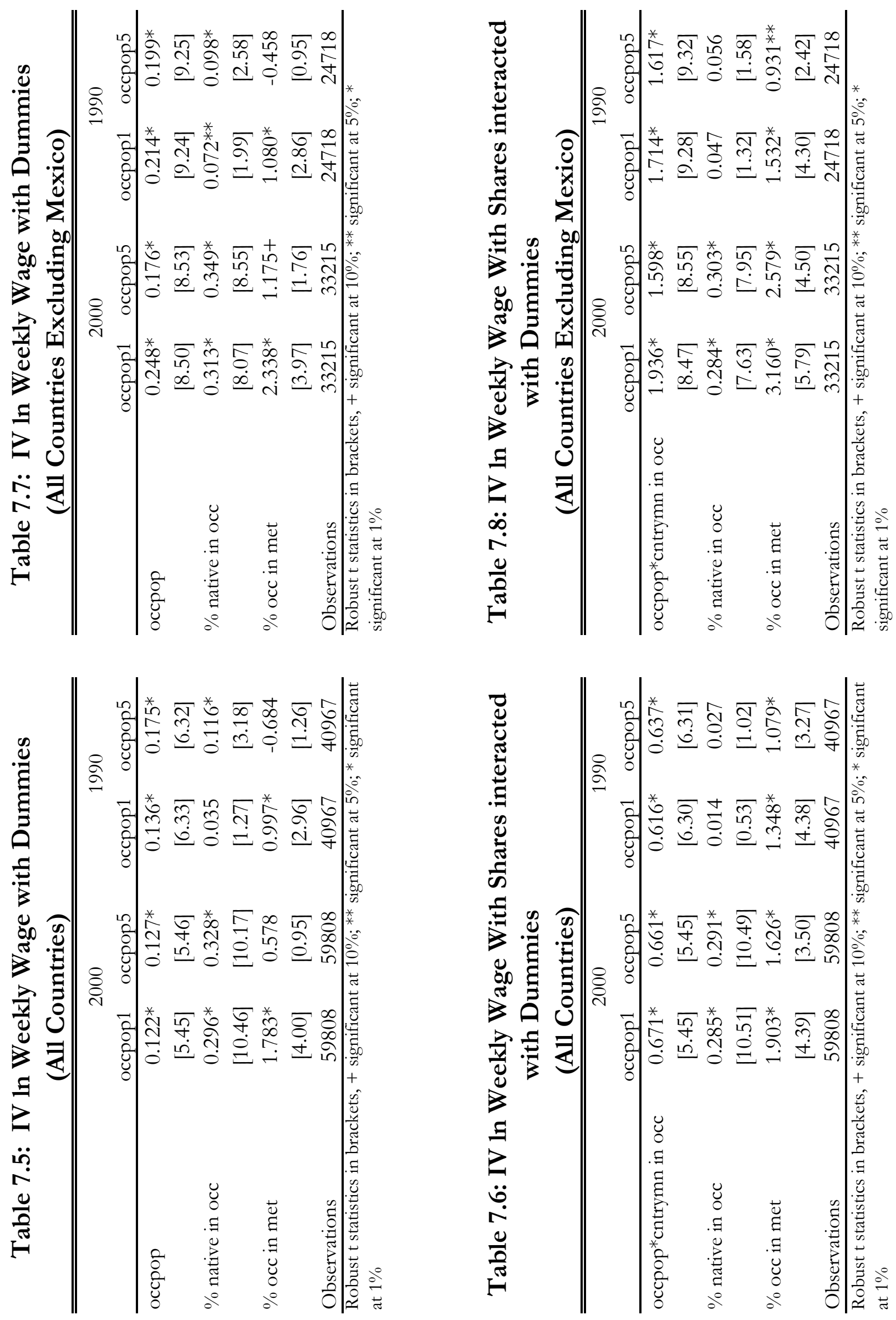


\section{Appendix}

Table A 4.1 Summary Statistics: All Countries

\begin{tabular}{|c|c|c|c|c|c|c|c|c|c|}
\hline & \multicolumn{3}{|c|}{2000} & \multicolumn{3}{|c|}{1990} & \multicolumn{3}{|c|}{1980} \\
\hline countries & 95 & & & 84 & & & 49 & & \\
\hline occupations & 326 & & & 341 & & & 273 & & \\
\hline \multirow[t]{2}{*}{ metropolitan areas } & 148 & & & 113 & & & 48 & & \\
\hline & Obs & Percent & & Obs & Percent & & Obs & Percent & \\
\hline Established Immigrants & 419037 & 81.51 & & 286852 & 80.137 & & 64187 & 81.860 & \\
\hline New Immigrants & 95084 & 18.49 & & 71101 & 19.863 & & 14224 & 18.140 & \\
\hline Total & 514121 & & & 357953 & & & 78411 & & \\
\hline Occupation Popularity & Obs & Percent & $\begin{array}{c}\% \text { estab cntry } \\
\text { in occ }\end{array}$ & Obs & Percent & $\begin{array}{c}\% \text { estab cntry } \\
\text { in occ }\end{array}$ & Obs & Percent & $\begin{array}{c}\% \text { estab cntry } \\
\text { in occ }\end{array}$ \\
\hline Top & 10439 & 12.147 & 12.449 & 6612 & 10.371 & 13.672 & 1774 & 14.688 & 15.860 \\
\hline Top2 & 16482 & 19.178 & 10.108 & 10647 & 16.700 & 10.874 & 2713 & 22.462 & 12.882 \\
\hline Top3 & 21388 & 24.887 & 8.901 & 14214 & 22.295 & 9.367 & 3467 & 28.705 & 11.244 \\
\hline Top4 & 25368 & 29.518 & 8.150 & 16815 & 26.374 & 8.559 & 3980 & 32.952 & 10.329 \\
\hline Top5 & 28934 & 33.667 & 7.582 & 19600 & 30.743 & 7.861 & 4463 & 36.951 & 9.585 \\
\hline Total population & 85942 & & & 63755 & & & 12078 & & \\
\hline Occupation Popularity & Obs & $\begin{array}{c}\text { mean wage } \\
\text { (hour) }\end{array}$ & $\begin{array}{c}\text { mean wage } \\
\text { (week) }\end{array}$ & Obs & $\begin{array}{c}\text { mean wage } \\
\text { (hour) }\end{array}$ & $\begin{array}{c}\text { mean wage } \\
\text { (week) }\end{array}$ & Obs & $\begin{array}{l}\text { mean } \\
\text { wage } \\
\text { (hour) }\end{array}$ & $\begin{array}{l}\text { mean wage } \\
\text { (week) }\end{array}$ \\
\hline Top & 10,061 & 16.253 & 673.714 & 6,427 & 9.776 & 401.185 & 1,726 & 5.787 & 226.625 \\
\hline Top2 & 15,934 & 15.478 & 637.685 & 10,299 & 9.417 & 381.577 & 2,631 & 5.615 & 219.053 \\
\hline Top3 & 20,670 & 15.147 & 620.951 & 13,740 & 9.136 & 367.189 & 3,373 & 5.611 & 212.379 \\
\hline Top4 & 24,501 & 14.914 & 610.432 & 16,257 & 9.047 & 361.948 & 3,873 & 5.594 & 212.190 \\
\hline Top5 & 27,900 & 14.857 & 606.206 & 18,959 & 8.884 & 354.019 & 4,344 & 5.555 & 209.060 \\
\hline Variable & Obs & Mean & Std. & Obs & Mean & Std. & Obs & Mean & Std. \\
\hline$\%$ estab countrymen in occ & 85942 & 0.035 & 0.047 & 63755 & 0.033 & 0.053 & 12078 & 0.043 & 0.071 \\
\hline$\%$ native in occ & 85887 & 0.596 & 0.221 & 63707 & 0.568 & 0.231 & 12065 & 0.651 & 0.204 \\
\hline$\%$ occ in met & 85942 & 0.012 & 0.011 & 63755 & 0.013 & 0.014 & 12078 & 0.015 & 0.017 \\
\hline age & 85942 & 30.640 & 10.472 & 63755 & 30.772 & 10.542 & 12078 & 30.937 & 10.771 \\
\hline female & 85942 & 1.336 & 0.472 & 63755 & 1.363 & 0.481 & 12078 & 1.374 & 0.484 \\
\hline english & 85942 & 0.499 & 0.500 & 63755 & 0.513 & 0.500 & 12078 & 0.484 & 0.500 \\
\hline mean edu of occupation & 85942 & 2.862 & 1.043 & 63755 & 2.630 & 0.875 & 12078 & 2.242 & 0.768 \\
\hline lnwage_hr & 73093 & 13.759 & 17.738 & 54122 & 8.675 & 9.697 & 10594 & 1.409 & 0.743 \\
\hline wage_wk & 73093 & 550.630 & 754.015 & 54122 & 338.033 & 380.143 & 10594 & 200.552 & 178.272 \\
\hline IV $\%$ estab countrymen in occ & 73031 & 0.037 & 0.060 & 49635 & 0.045 & 0.081 & 8100 & 0.059 & 0.093 \\
\hline IV $\%$ native in occ & 72933 & 0.685 & 0.214 & 49583 & 0.694 & 0.192 & 8090 & 0.756 & 0.167 \\
\hline IV $\%$ occ in met & 73031 & 0.012 & 0.014 & 49635 & 0.015 & 0.017 & 8100 & 0.019 & 0.019 \\
\hline occpop $1 *$ countrymen in occ & 82944 & 0.015 & 0.049 & 61194 & 0.014 & 0.055 & 11733 & 0.023 & 0.075 \\
\hline occpop $2 *$ countrymen in occ & 82944 & 0.020 & 0.051 & 61194 & 0.018 & 0.056 & 11733 & 0.029 & 0.076 \\
\hline occpop $3^{*}$ countrymen in occ & 82944 & 0.022 & 0.051 & 61194 & 0.021 & 0.056 & 11733 & 0.032 & 0.076 \\
\hline occpop $4 *$ countrymen in occ & 82944 & 0.024 & 0.051 & 61194 & 0.023 & 0.056 & 11733 & 0.034 & 0.075 \\
\hline occpop $5^{*}$ countrymen in occ & 82944 & 0.026 & 0.051 & 61194 & 0.024 & 0.056 & 11733 & 0.036 & 0.075 \\
\hline Education & Obs & Percent & & Obs & percent & & Obs & Percent & \\
\hline No Diploma & 39493 & 0.460 & & 30505 & 47.847 & & 6664 & 55.175 & \\
\hline High School & 16029 & 0.187 & & 12193 & 19.125 & & 2105 & 17.428 & \\
\hline Some College & 8626 & 0.100 & & 7245 & 11.364 & & 1344 & 11.128 & \\
\hline Associates Degress & 2627 & 0.031 & & 2915 & 4.572 & & - & - & \\
\hline College & 8171 & 0.095 & & 6945 & 10.893 & & 1965 & 16.269 & \\
\hline Graduate Degree & 9331 & 0.109 & & 3952 & 6.199 & & - & - & \\
\hline Total & 85942 & & & 63755 & & & 12078 & & \\
\hline Marital Status & Obs & Percent & & Obs & Percent & & Obs & Percent & \\
\hline Married, Spouse Present & 31645 & 36.821 & & 23878 & 0.375 & 37.453 & 6000 & 49.68 & \\
\hline Married, Spouse Absent & 10948 & 12.739 & & 7499 & 0.118 & 11.762 & 1003 & 8.30 & \\
\hline Separated & 2268 & 2.639 & & 1938 & 0.030 & 3.040 & 388 & 3.21 & \\
\hline Divorced & 2629 & 3.059 & & 1800 & 0.028 & 2.823 & 304 & 2.52 & \\
\hline Widowed & 715 & 0.832 & & 705 & 0.011 & 1.106 & 145 & 1.20 & \\
\hline Never Married/Sigle & 37737 & 43.910 & & 27935 & 0.438 & 43.816 & 4238 & 35.09 & \\
\hline Total & 85942 & & & 63755 & & & 12078 & & \\
\hline
\end{tabular}


Table A 4.2 Summary Statistics: All Countries Except for Mexico

\begin{tabular}{|c|c|c|c|c|c|c|c|c|c|}
\hline & \multicolumn{3}{|c|}{2000} & \multicolumn{3}{|c|}{1990} & \multicolumn{3}{|c|}{1980} \\
\hline countries & 94 & & & 83 & & & 48 & & \\
\hline occupations & 300 & & & 319 & & & 238 & & \\
\hline metropolitan areas & 97 & & & 85 & & & 33 & & \\
\hline & Obs & Percent & & Obs & Percent & & Obs & Percent & \\
\hline Established Immigrants & 287646 & 84.147 & & 214481 & 81.826 & & 50969 & 85.015 & \\
\hline New Immigrants & 54190 & 15.853 & & 47636 & 18.174 & & 8984 & 14.985 & \\
\hline Total & 341836 & & & 262117 & & & 59953 & & \\
\hline Occupation Popularity & Obs & Percent & $\begin{array}{c}\% \text { estab cntry } \\
\text { in occ }\end{array}$ & Obs & Percent & $\begin{array}{c}\% \text { estab cntry } \\
\text { in occ }\end{array}$ & Obs & Percent & $\begin{array}{c}\% \text { estab cntry } \\
\text { in occ }\end{array}$ \\
\hline Top & 5529 & 11.814 & 10.982 & 3982 & 9.696 & 9.764 & 998 & 14.019 & 12.323 \\
\hline Top2 & 8629 & 18.437 & 9.222 & 6547 & 15.942 & 8.384 & 1545 & 21.702 & 10.641 \\
\hline Top3 & 11254 & 24.046 & 8.177 & 8636 & 21.029 & 7.540 & 1965 & 27.602 & 9.541 \\
\hline Top4 & 13315 & 28.450 & 7.514 & 10219 & 24.883 & 6.991 & 2306 & 32.392 & 8.782 \\
\hline Top5 & 15325 & 32.744 & 6.968 & 11834 & 28.816 & 6.501 & 2621 & 36.817 & 8.146 \\
\hline Total population & 46802 & & & 41068 & & & 7119 & & \\
\hline Occupation Popularity & Obs & $\begin{array}{c}\text { mean wage } \\
\text { (hour) }\end{array}$ & $\begin{array}{c}\text { mean wage } \\
\text { (week) }\end{array}$ & Obs & $\begin{array}{c}\text { mean wage } \\
\text { (hour) }\end{array}$ & $\begin{array}{c}\text { mean wage } \\
\text { (week) }\end{array}$ & Obs & $\begin{array}{c}\text { mean wage } \\
\text { (hour) }\end{array}$ & $\begin{array}{c}\text { mean wage } \\
\text { (week) }\end{array}$ \\
\hline Top & 5,241 & 22.725 & 955.142 & 3,826 & 12.129 & 505.856 & 956 & 6.818 & 273.832 \\
\hline Top2 & 8,230 & 21.419 & 894.256 & 6,267 & 11.525 & 471.756 & 1,471 & 6.581 & 262.953 \\
\hline Top3 & 10,755 & 20.718 & 860.103 & 8,253 & 11.182 & 454.341 & 1,880 & 6.548 & 253.395 \\
\hline Top4 & 12,728 & 20.254 & 840.164 & 9,769 & 10.998 & 444.435 & 2,211 & 6.426 & 248.692 \\
\hline Top5 & 14,638 & 20.025 & 827.540 & 11,320 & 10.767 & 433.266 & 2,516 & 6.344 & 242.584 \\
\hline Variable & Obs & Mean & Std. & Obs & Mean & Std. & Obs & Mean & Std. \\
\hline$\%$ estab countrymen in occ & 46802 & 0.031 & 0.037 & 41068 & 0.027 & 0.032 & 7119 & 0.038 & 0.045 \\
\hline$\%$ native in occ & 46785 & 0.630 & 0.206 & 41057 & 0.607 & 0.222 & 7113 & 0.669 & 0.202 \\
\hline$\%$ occ in met & 46802 & 0.013 & 0.011 & 41068 & 0.014 & 0.014 & 7119 & 0.016 & 0.018 \\
\hline age & 46802 & 33.301 & 10.772 & 41068 & 33.022 & 10.831 & 7119 & 33.614 & 11.066 \\
\hline female & 46802 & 1.414 & 0.493 & 41068 & 1.428 & 0.495 & 7119 & 1.453 & 0.498 \\
\hline english & 46802 & 0.694 & 0.461 & 41068 & 0.635 & 0.481 & 7119 & 0.651 & 0.477 \\
\hline mean edu of occupation & 46802 & 3.296 & 1.154 & 41068 & 2.842 & 0.964 & 7119 & 2.478 & 0.871 \\
\hline lnwage_hr & 40974 & 17.294 & 20.670 & 35197 & 9.986 & 11.003 & 6236 & 6.172 & 6.591 \\
\hline wage_wk & 40974 & 699.702 & 901.209 & 35197 & 391.167 & 439.558 & 6236 & 228.152 & 204.458 \\
\hline IV \% estab countrymen in occ & 40121 & 0.029 & 0.036 & 29963 & 0.0376 & 0.0471 & 4348 & 0.055 & 0.062 \\
\hline IV $\%$ native in occ & 40111 & 0.706 & 0.192 & 29952 & 0.7078 & 0.1886 & 4342 & 0.736 & 0.178 \\
\hline IV $\%$ occ in met & 40121 & 0.013 & 0.013 & 29963 & 0.0159 & 0.0169 & 4348 & 0.021 & 0.020 \\
\hline occpop $1 *$ countrymen in occ & 45000 & 0.013 & 0.039 & 39235 & 0.010 & 0.032 & 6859 & 0.017 & 0.047 \\
\hline occpop $2 *$ countrymen in occ & 45000 & 0.017 & 0.041 & 39235 & 0.013 & 0.034 & 6859 & 0.023 & 0.049 \\
\hline occpop $3 *$ countrymen in occ & 45000 & 0.020 & 0.041 & 39235 & 0.016 & 0.035 & 6859 & 0.026 & 0.050 \\
\hline occpop $4 *$ countrymen in occ & 45000 & 0.021 & 0.041 & 39235 & 0.017 & 0.035 & 6859 & 0.028 & 0.049 \\
\hline occpop $5 *$ countrymen in occ & 45000 & 0.023 & 0.041 & 39235 & 0.019 & 0.035 & 6859 & 0.030 & 0.049 \\
\hline Education & Obs & Percent & & Obs & percent & & Obs & Percent & \\
\hline No Diploma & 11598 & 24.781 & & 13749 & 47.847 & & 2473 & 34.738 & \\
\hline High School & 8964 & 19.153 & & 8839 & 19.125 & & 1624 & 22.812 & \\
\hline Some College & 6193 & 13.232 & & 5843 & 11.364 & & 1145 & 16.084 & \\
\hline Associates Degress & 2205 & 4.711 & & 2442 & 4.572 & & - & - & \\
\hline College & 10149 & 21.685 & & 6545 & 10.893 & & 1877 & 26.366 & \\
\hline Graduate Degree & 7693 & 16.437 & & 3650 & 6.199 & & - & - & \\
\hline Total & 46802 & & & 41068 & & & 7119 & & \\
\hline Marital Status & Freq. & Percent & & Obs & Percent & & Obs & Percent & \\
\hline Married, Spouse Present & 21192 & 45.280 & & 17880 & 37.453 & & 4019 & 56.455 & \\
\hline Married, Spouse Absent & 4404 & 9.410 & & 4229 & 11.762 & & 498 & 6.995 & \\
\hline Separated & 1177 & 2.515 & & 1369 & 3.040 & & 228 & 3.203 & \\
\hline Divorced & 1843 & 3.938 & & 1473 & 2.823 & & 222 & 3.118 & \\
\hline Widowed & 464 & 0.991 & & 539 & 1.106 & & 102 & 1.433 & \\
\hline Never Married/Sigle & 17722 & 37.866 & & 15578 & 43.816 & & 2050 & 28.796 & \\
\hline Total & 46802 & & & 41068 & & & 7119 & & \\
\hline
\end{tabular}




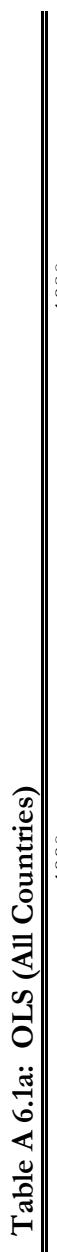

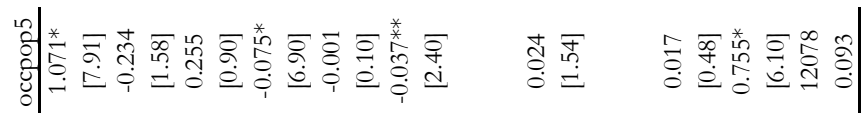

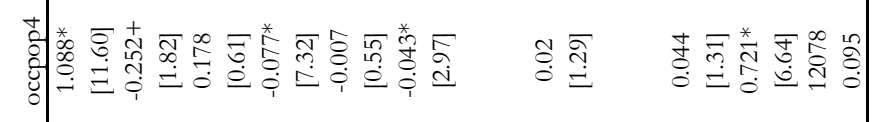

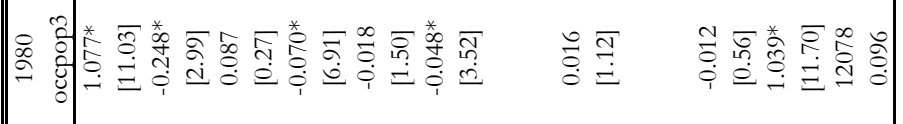

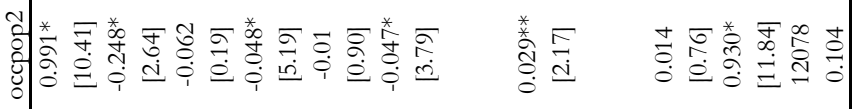

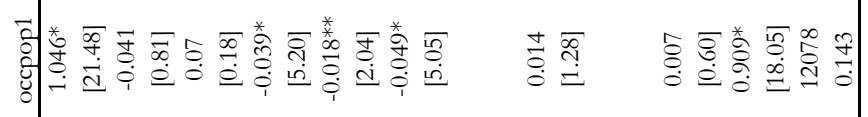

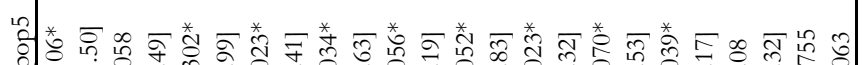

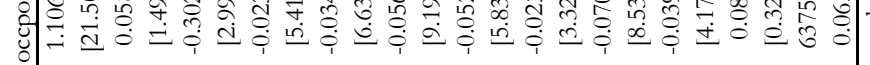

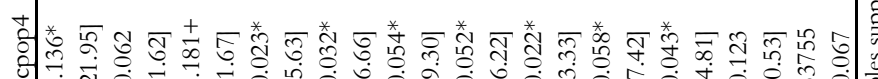

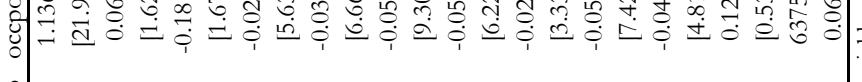

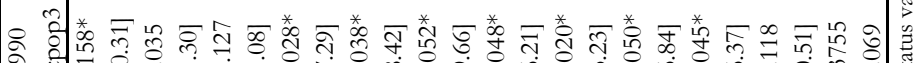

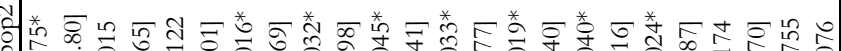

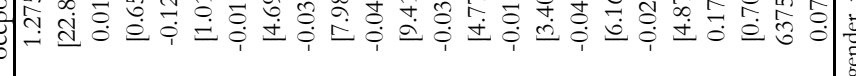

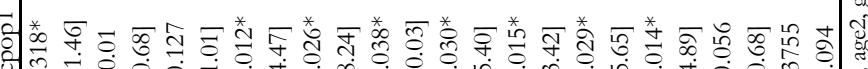
䒺产

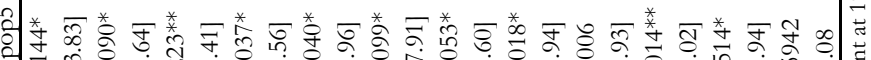

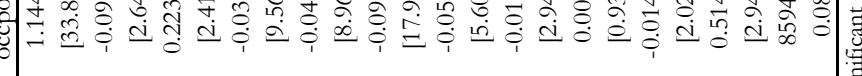

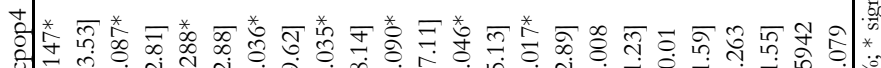

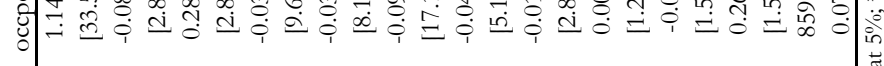

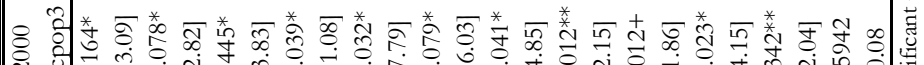

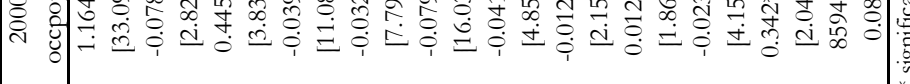

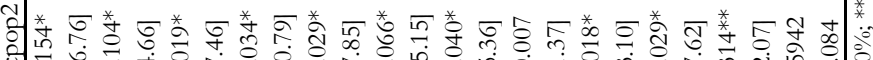

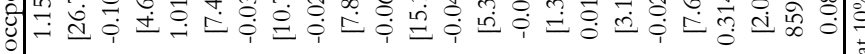

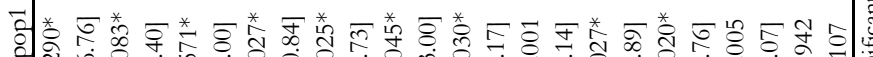

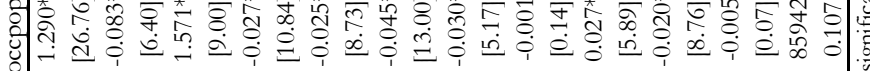
刎

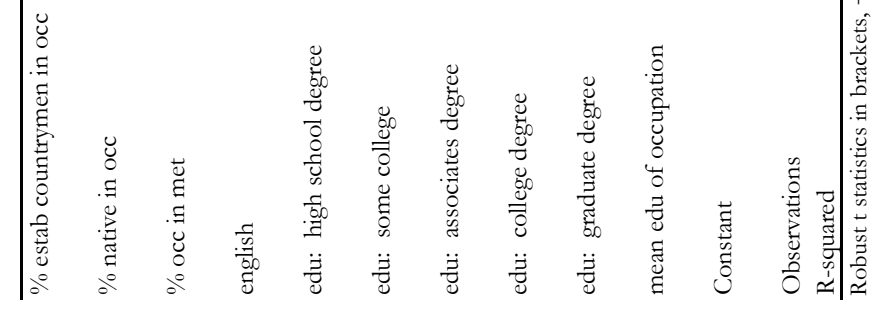

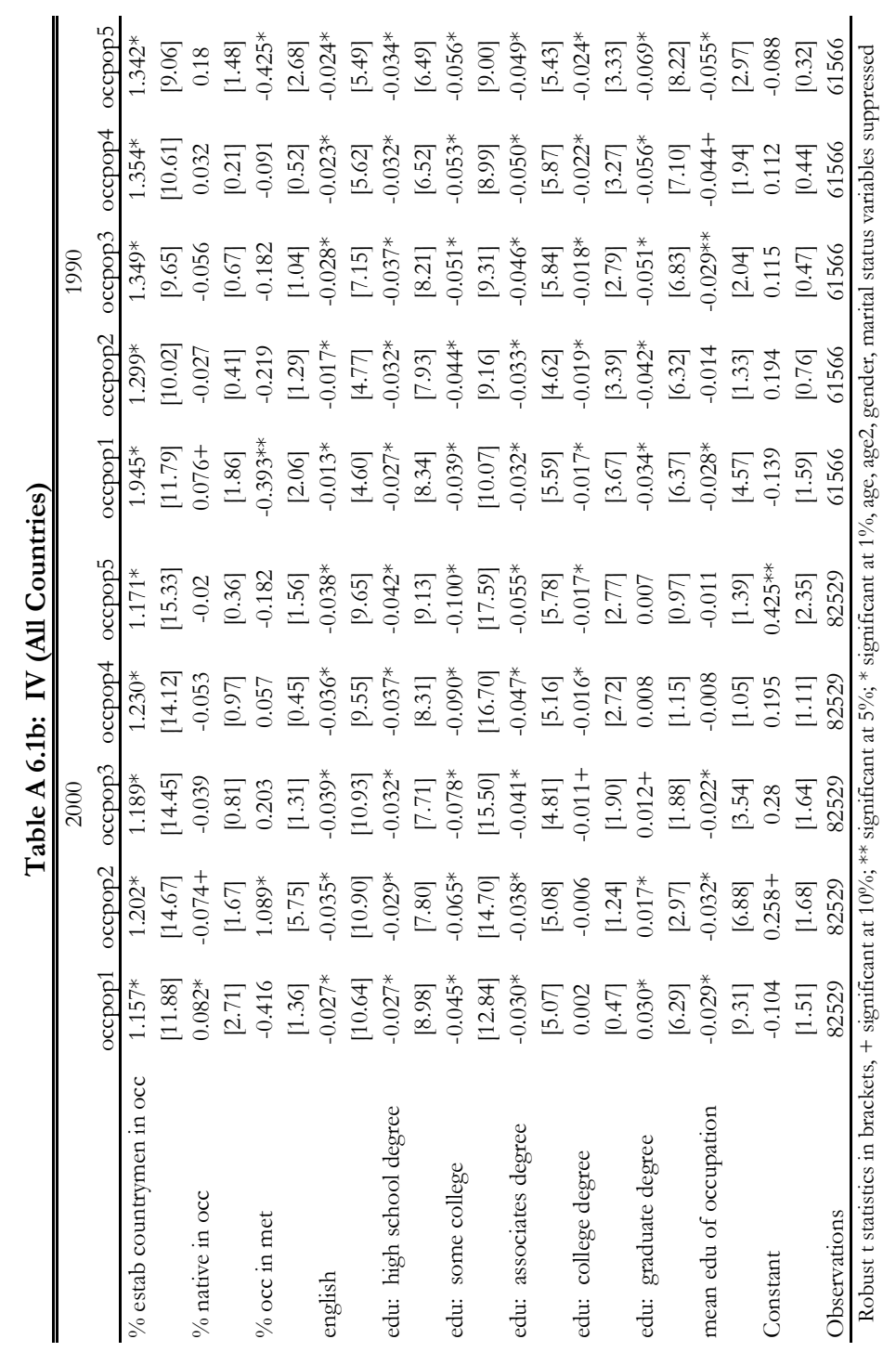




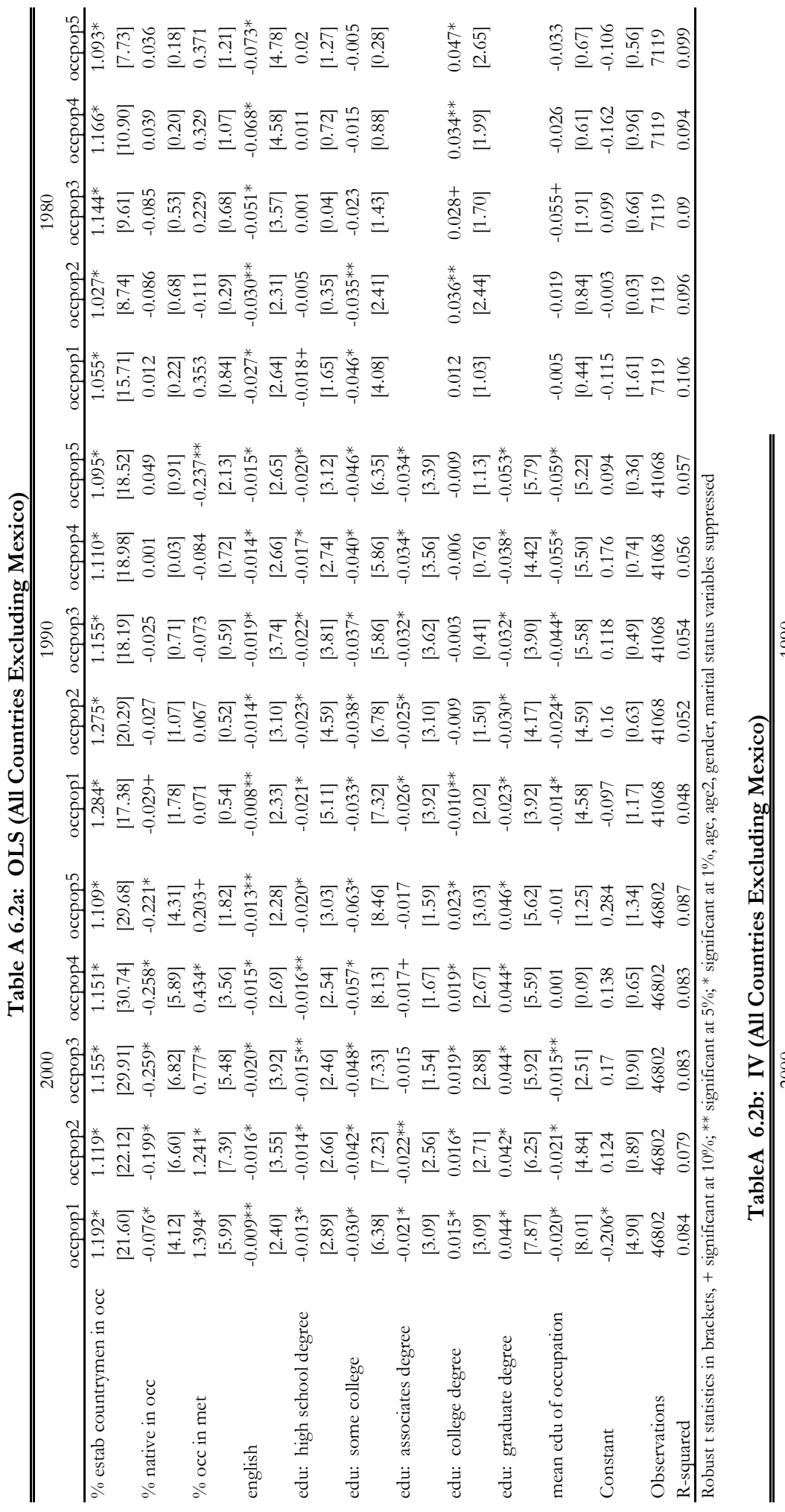

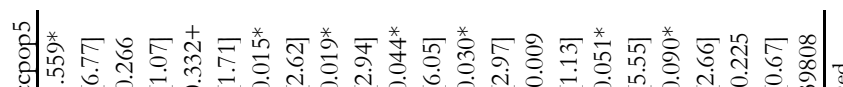

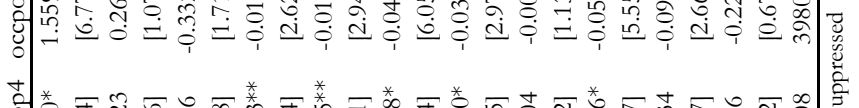

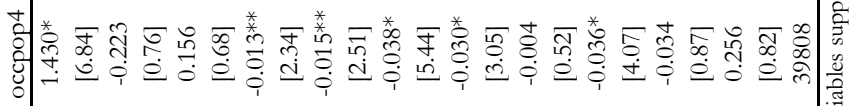

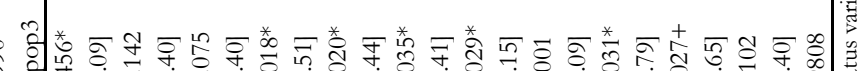

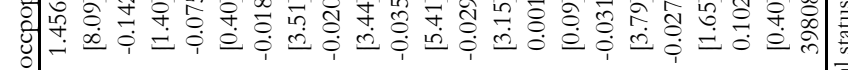

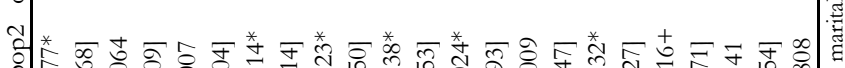

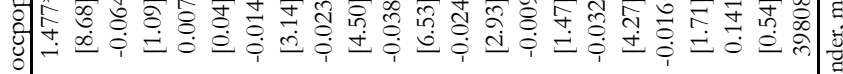

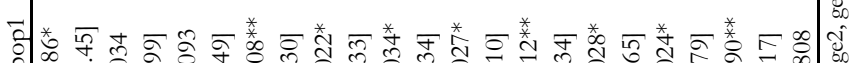

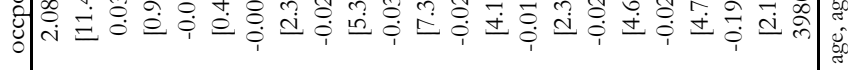
设

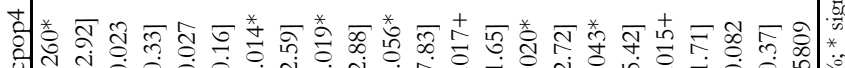

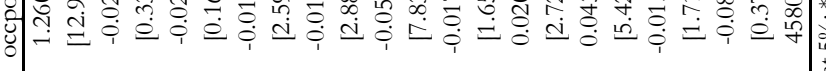

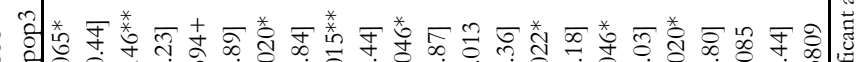

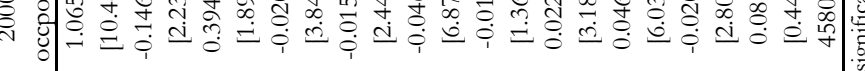

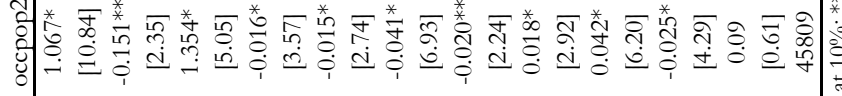

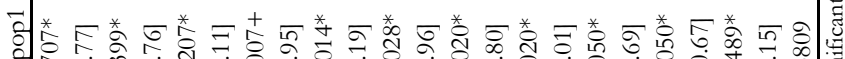

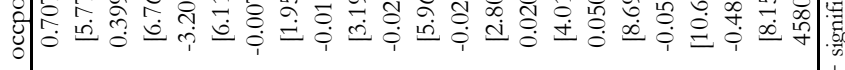

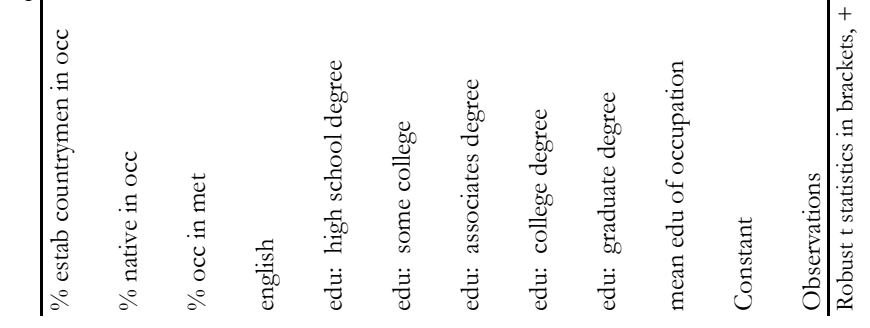




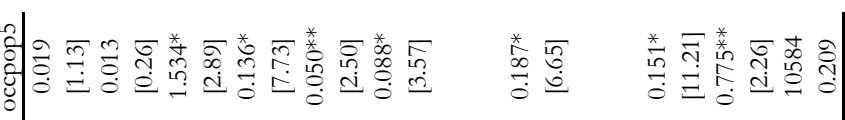

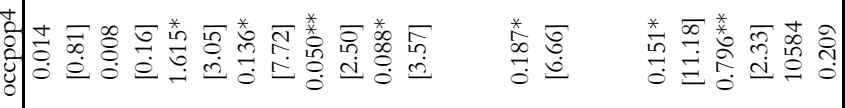

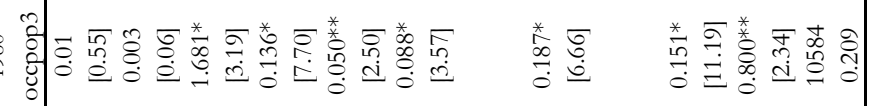

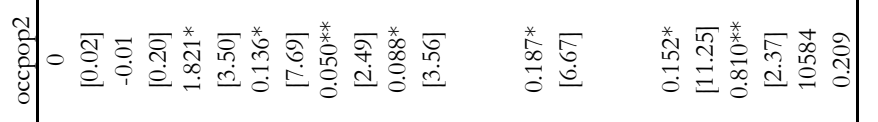

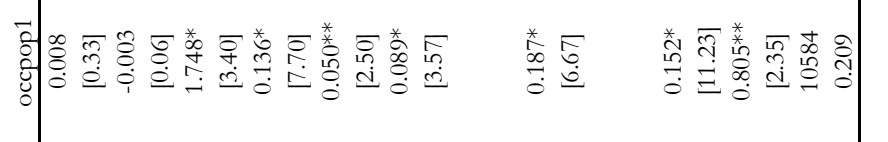

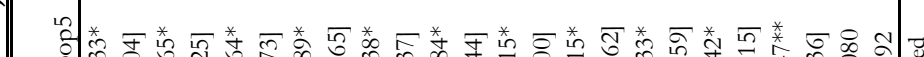

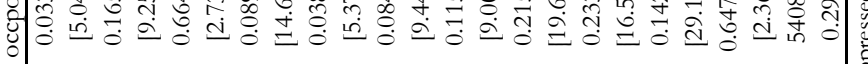

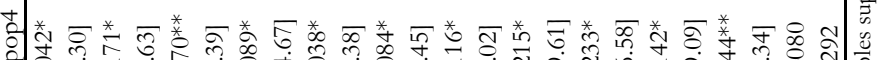

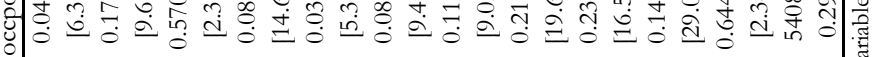

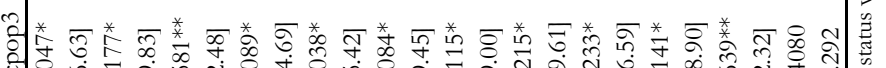

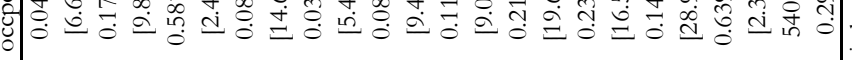

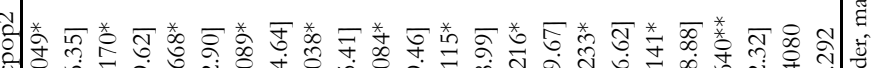

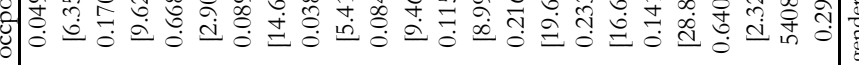

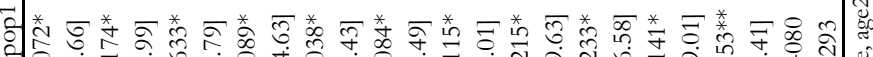

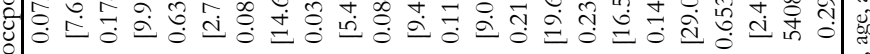

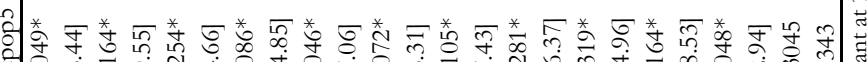
의의

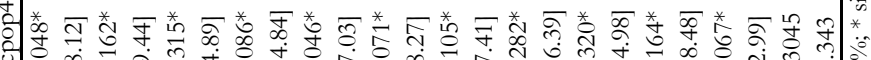

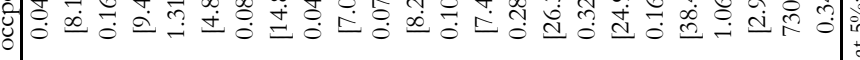

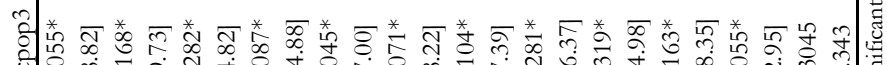

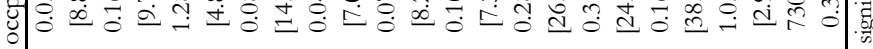

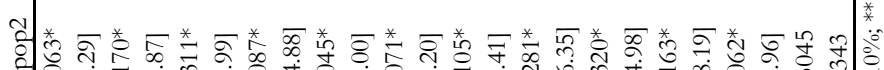

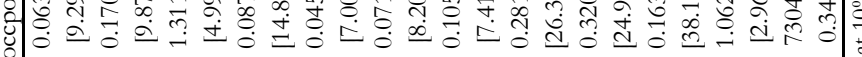

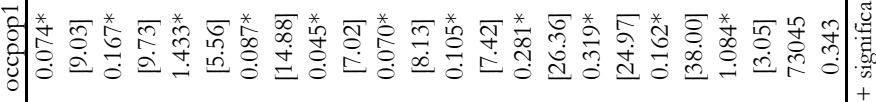

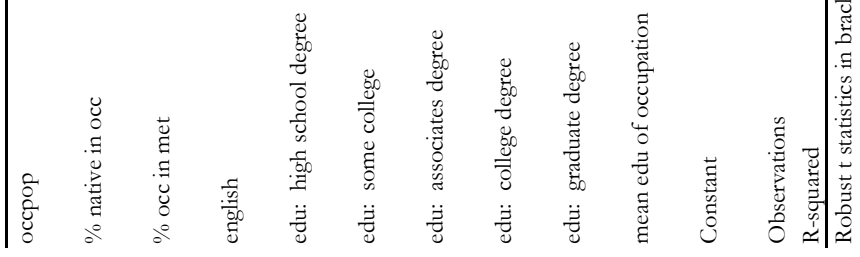

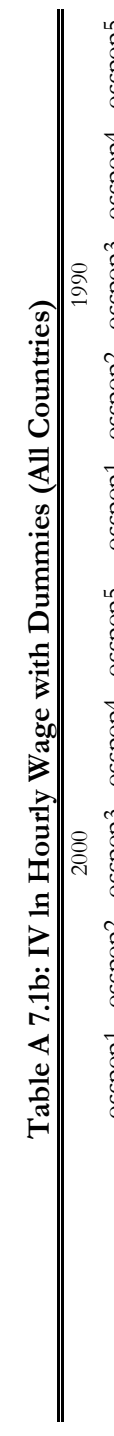

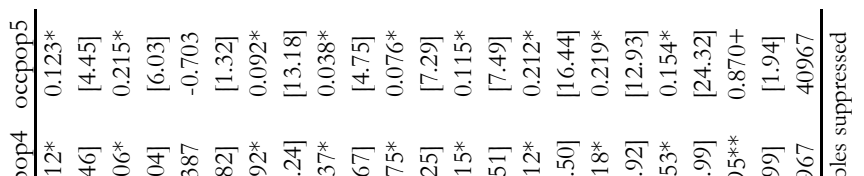

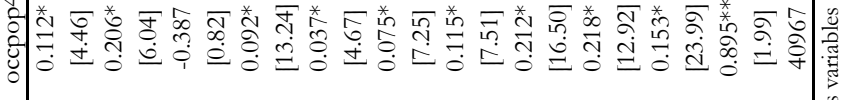

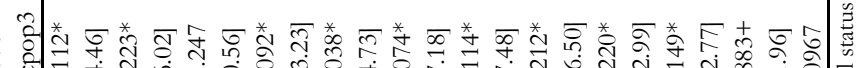

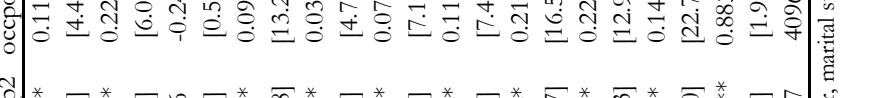

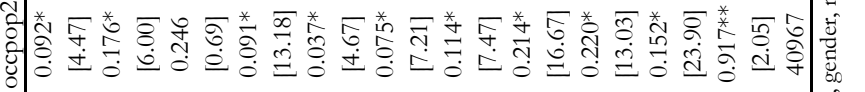

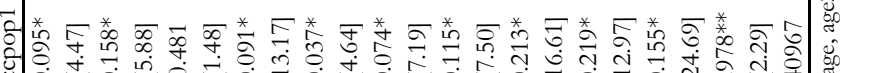

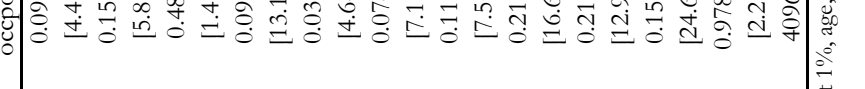

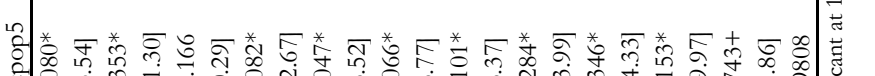

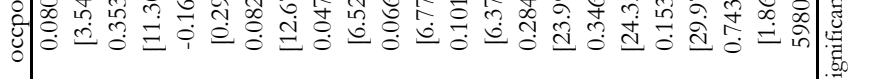

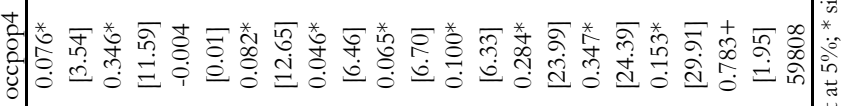

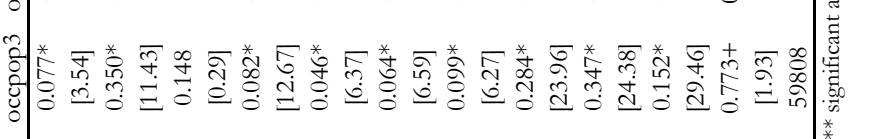

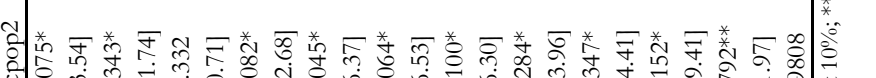

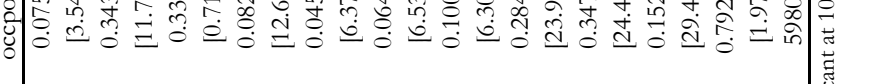

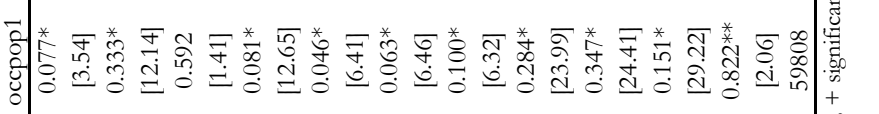

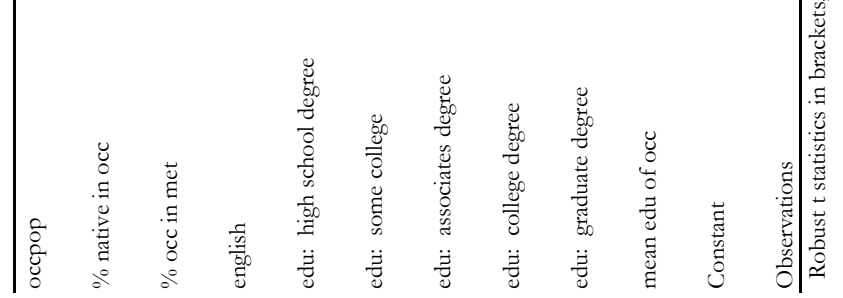



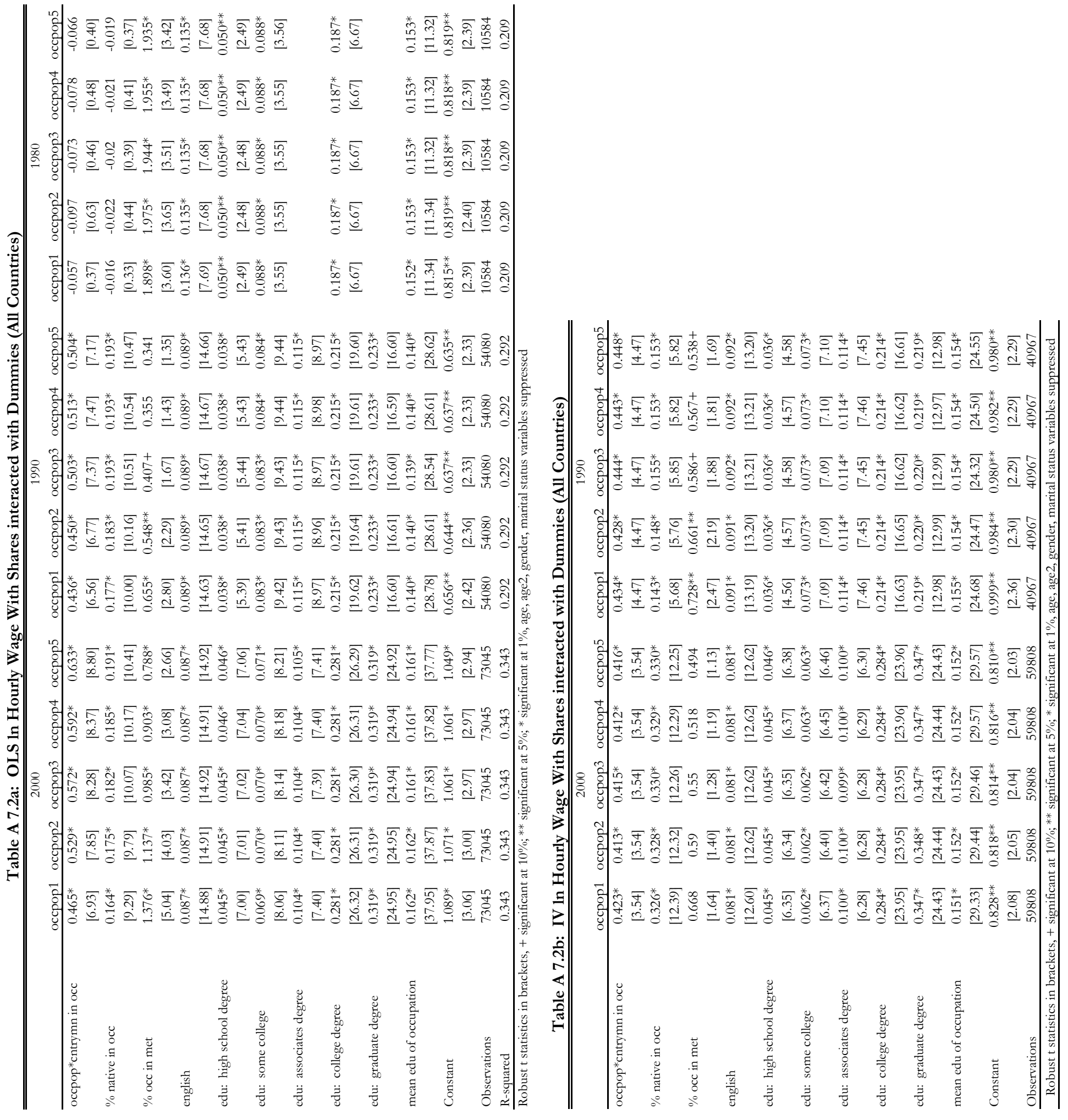


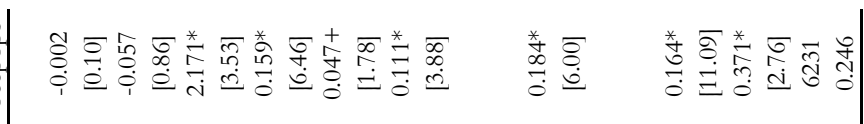

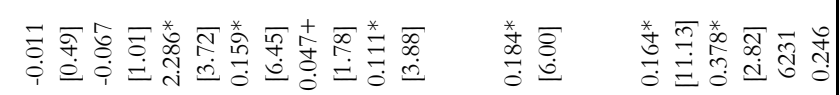

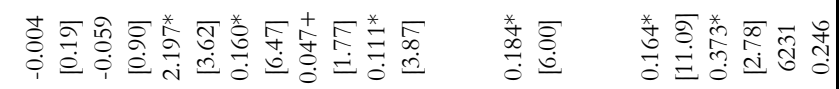

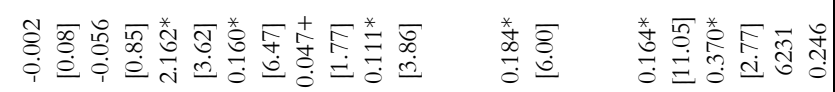

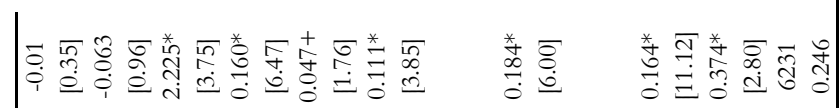
苟 范范

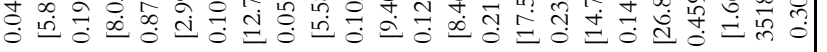

*

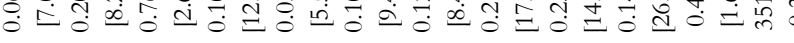

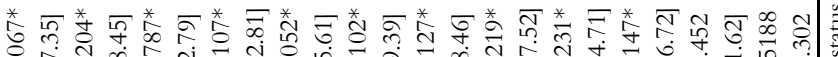

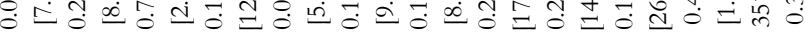
苞

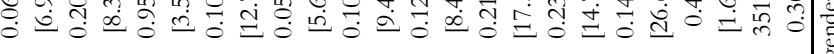
荵 虽

*

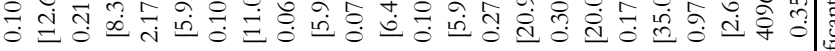

*

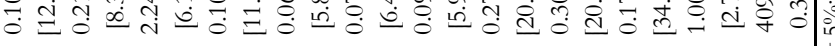
*

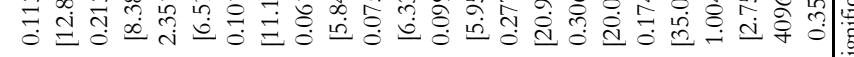

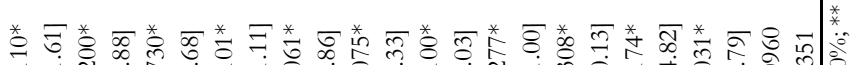

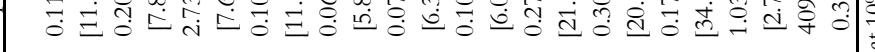

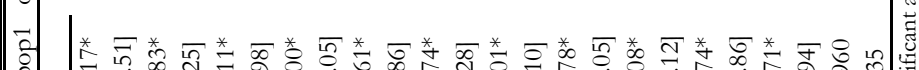
난)

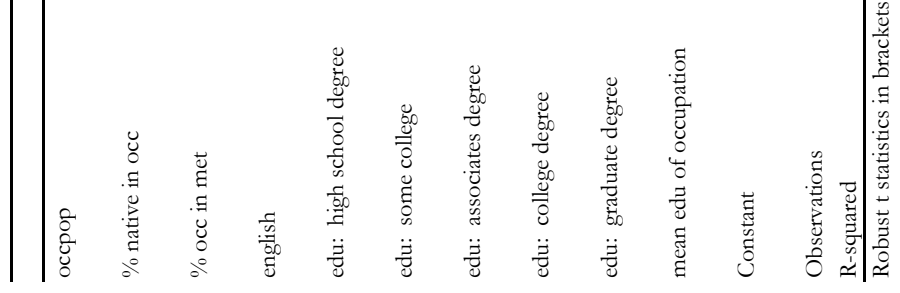

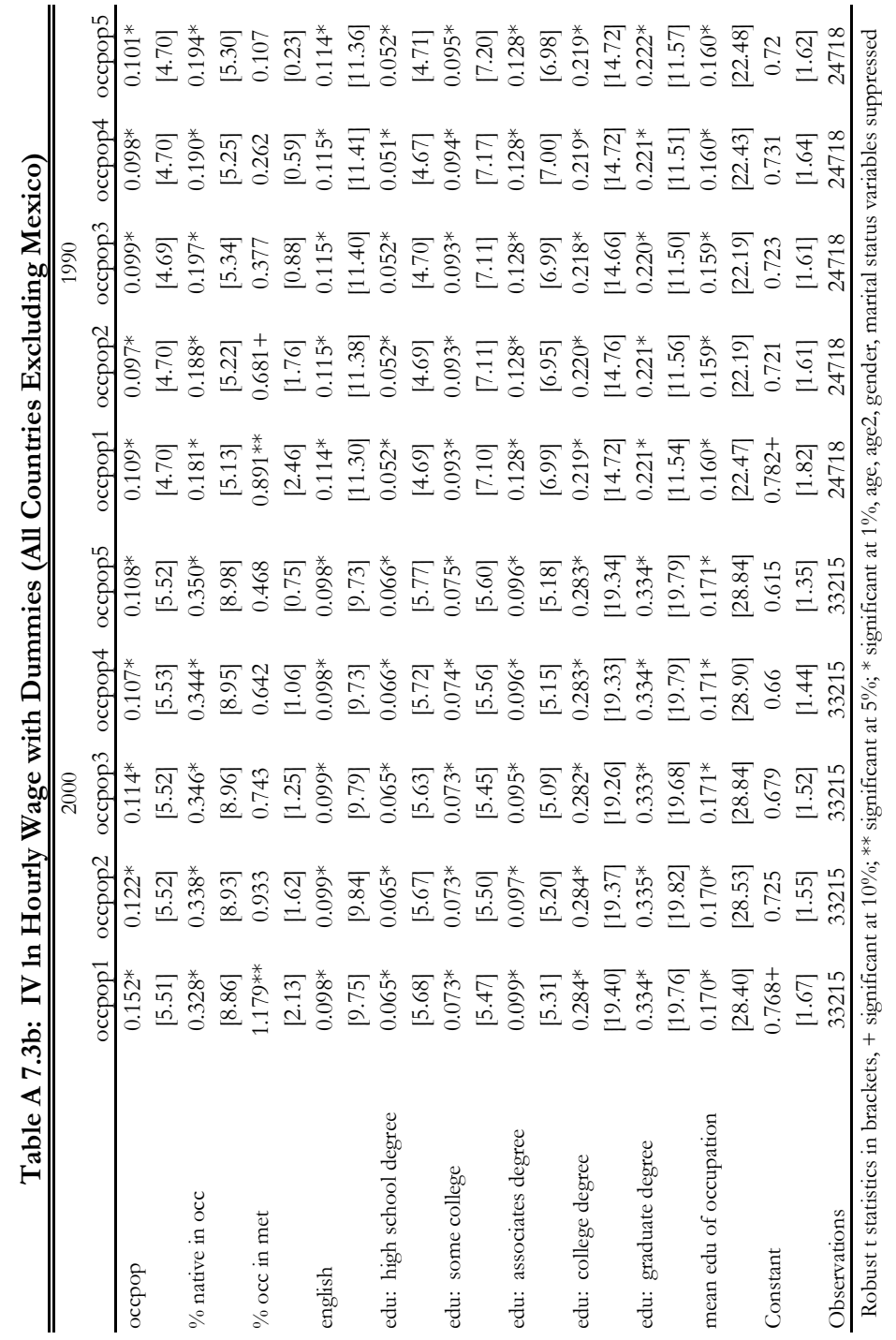



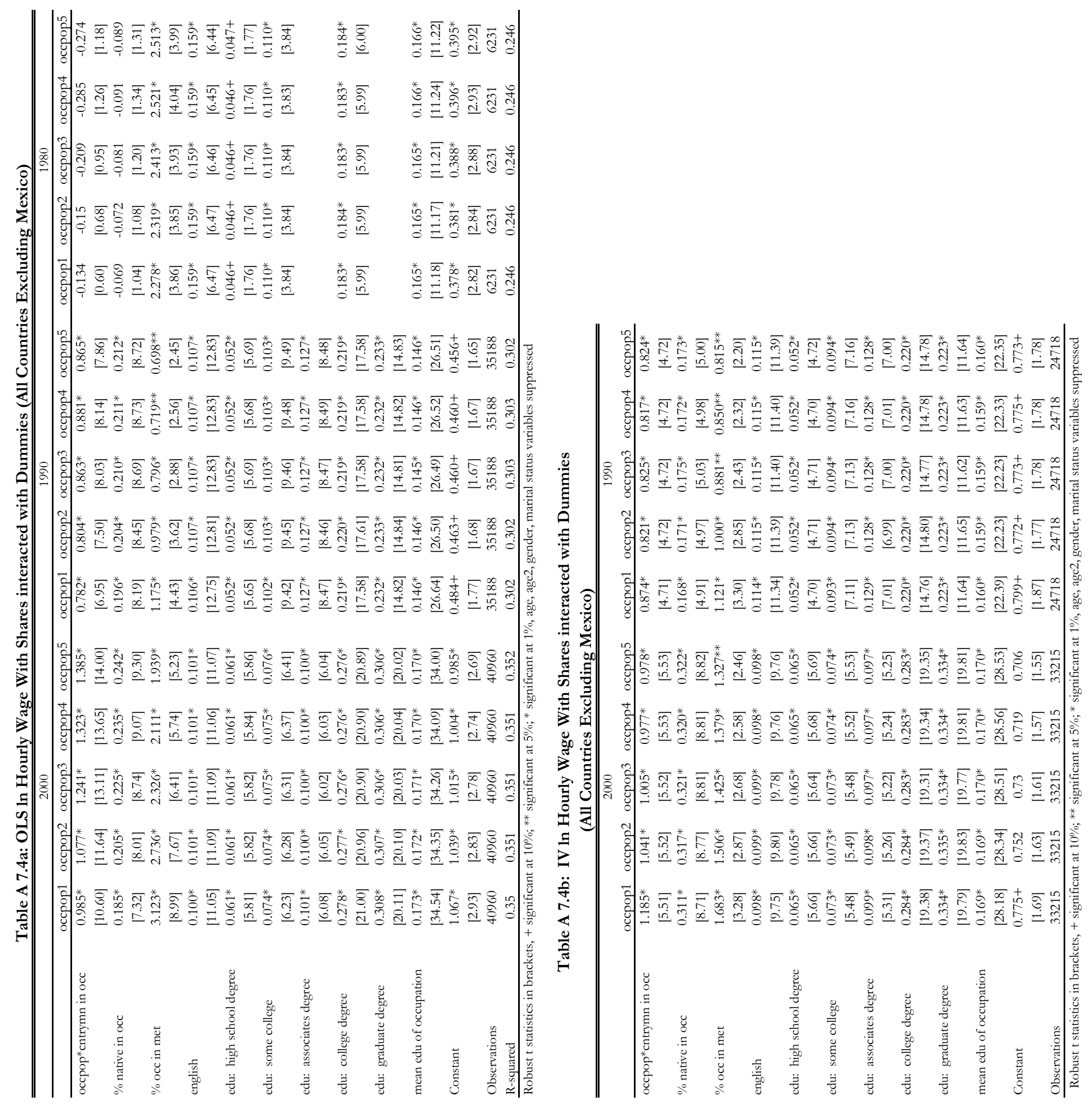


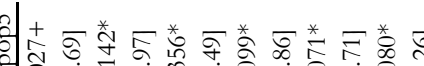

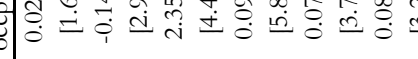

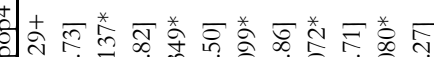

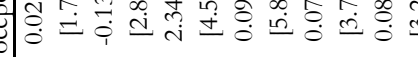

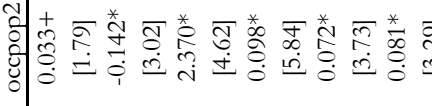

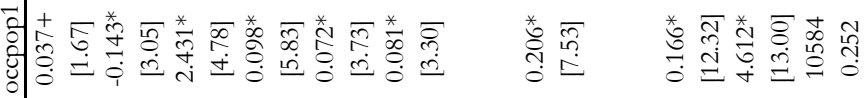

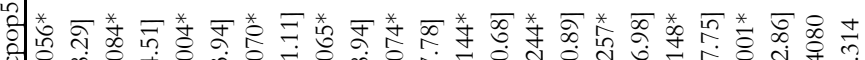

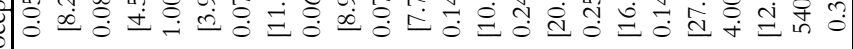

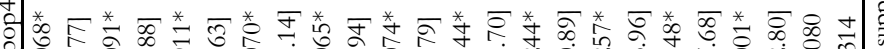

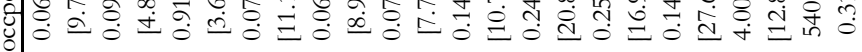

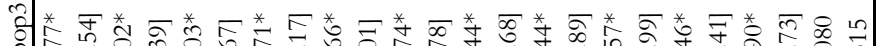

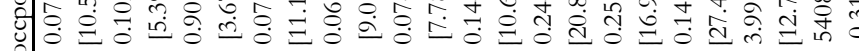

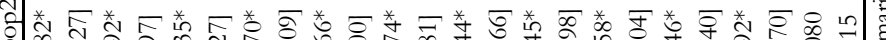

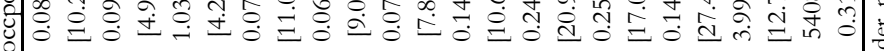

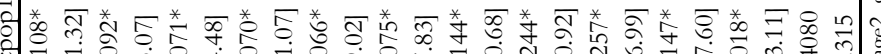

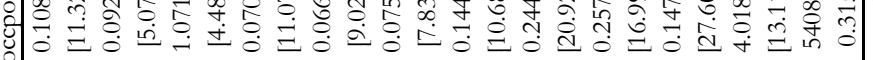

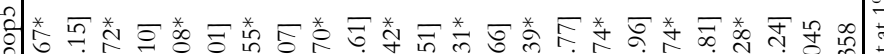

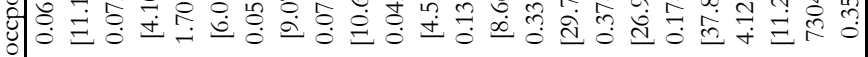

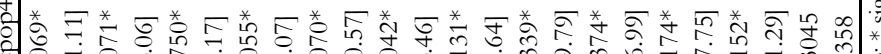

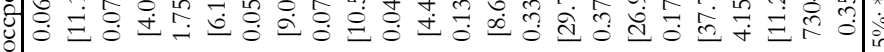

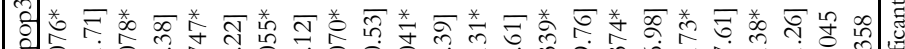

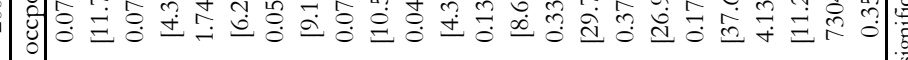

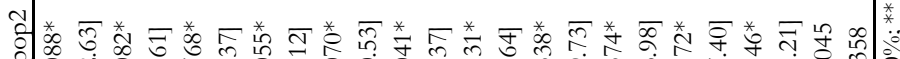

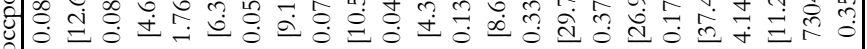

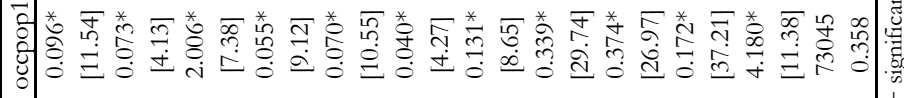

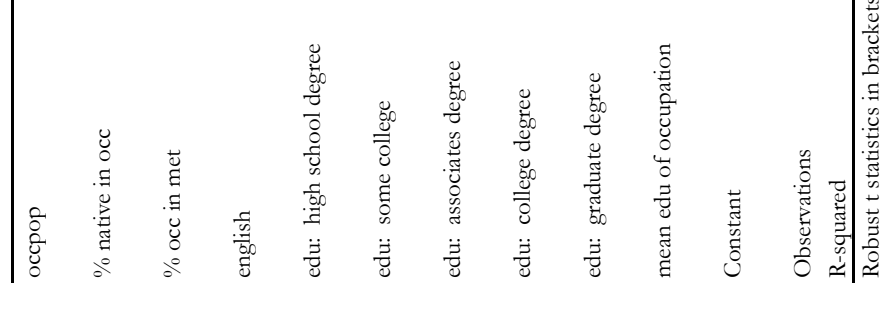

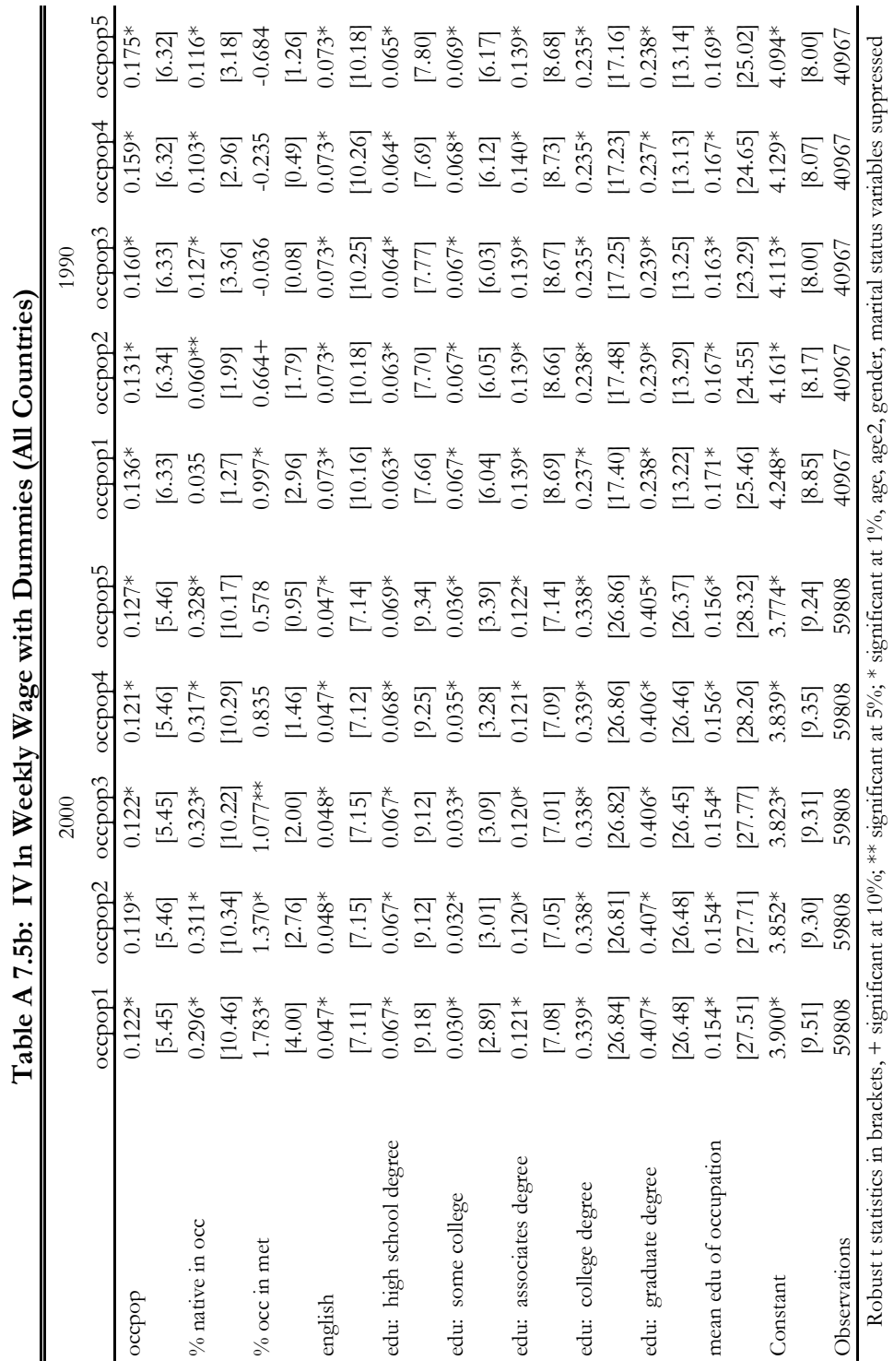




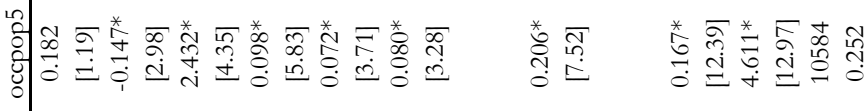

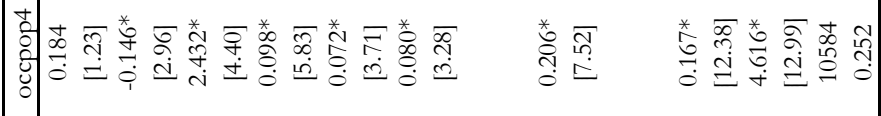

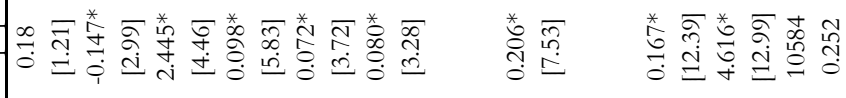

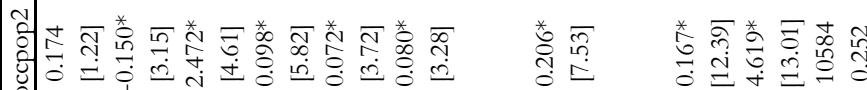

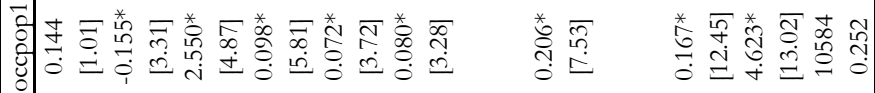

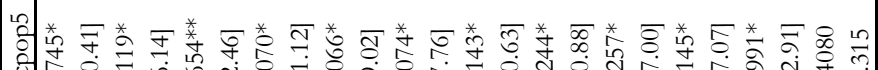

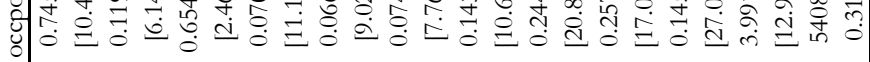

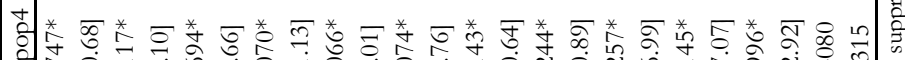
岛苍它

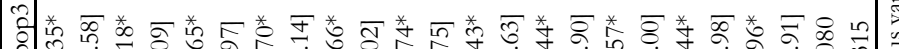

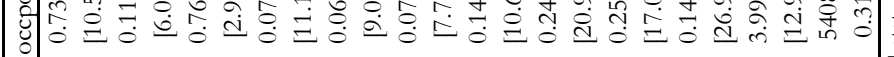

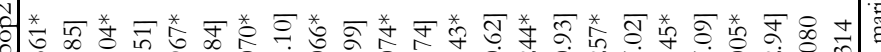

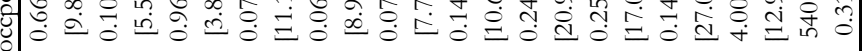

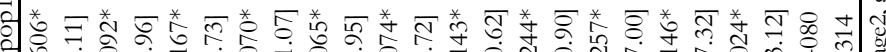

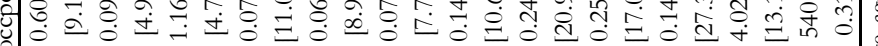

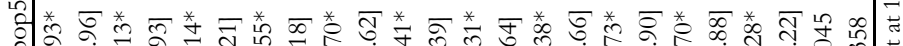

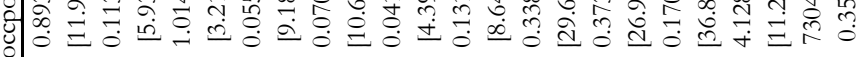

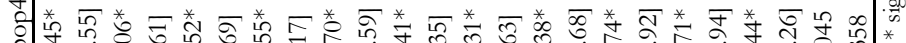

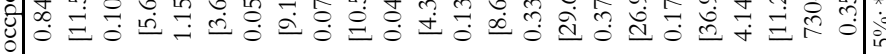

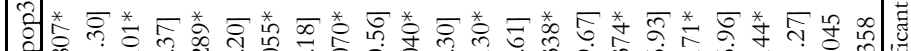

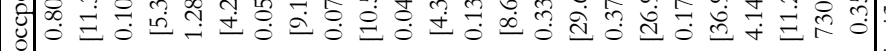

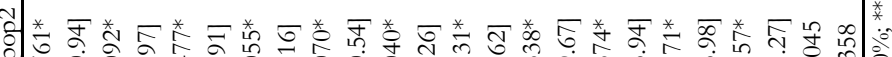

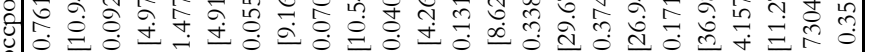

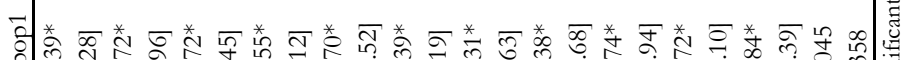

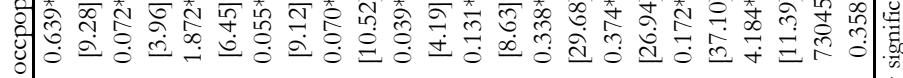

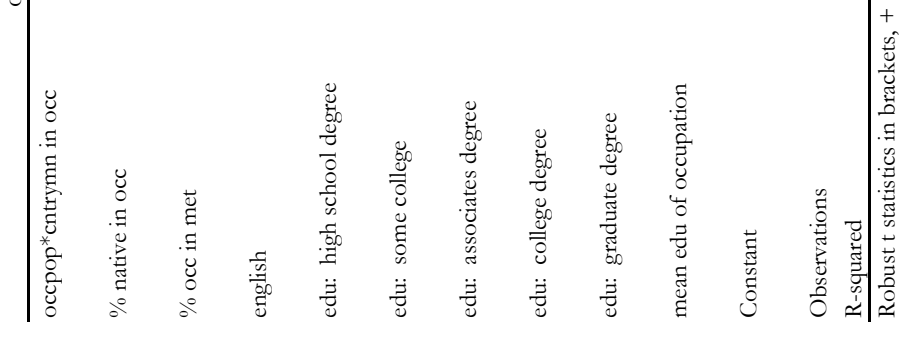

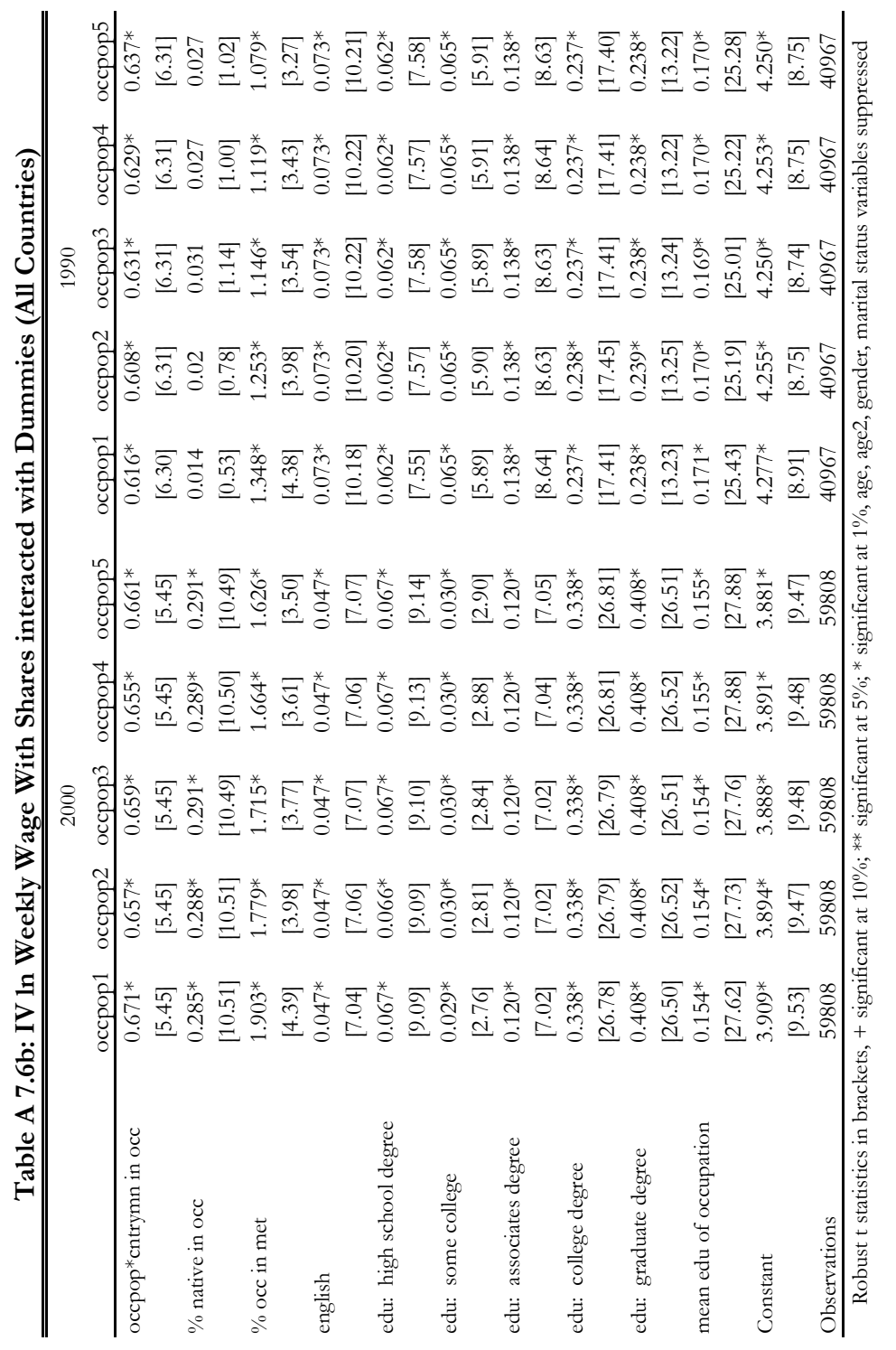




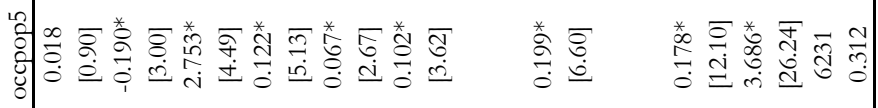

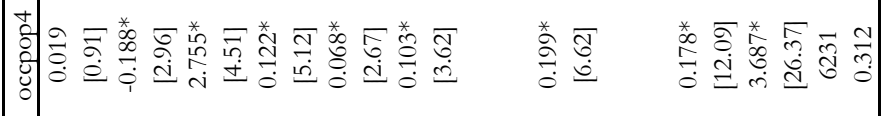

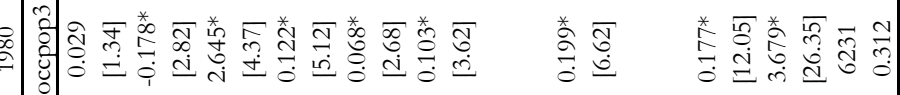

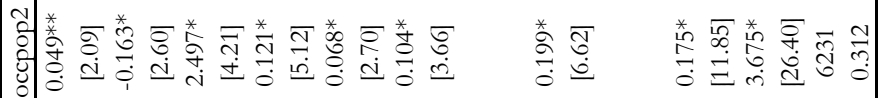

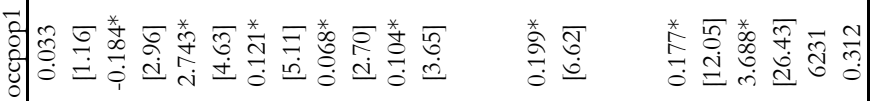

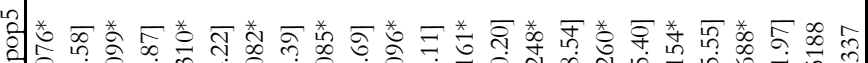

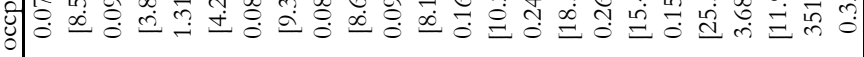

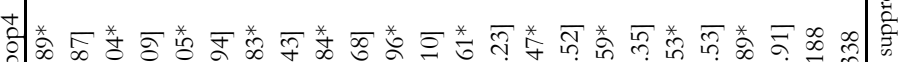

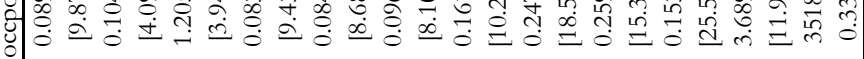

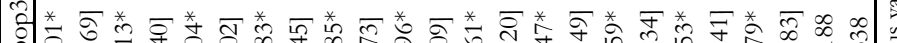

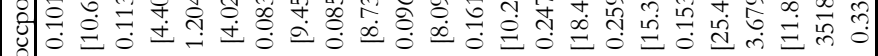

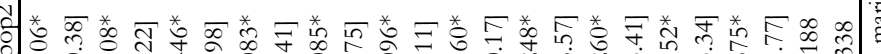

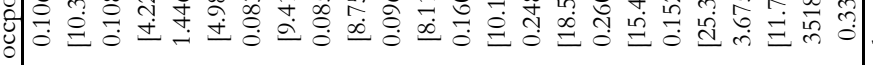

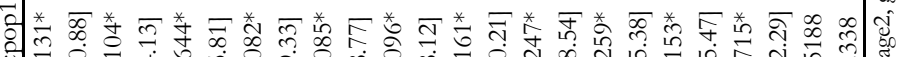

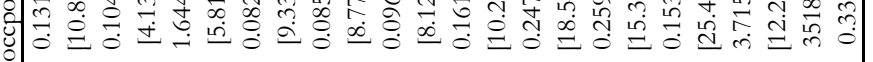

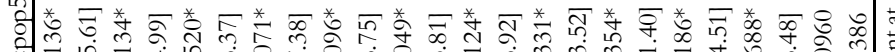

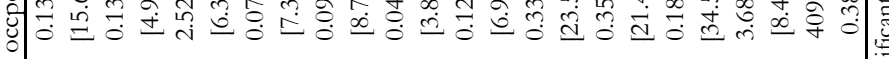

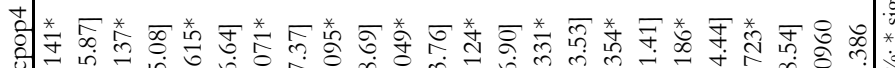

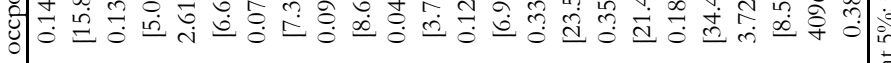

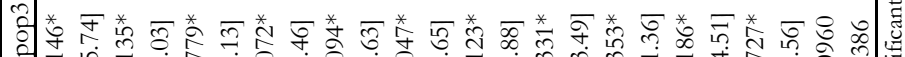

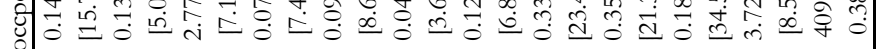

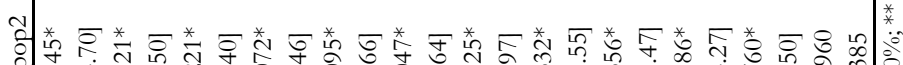

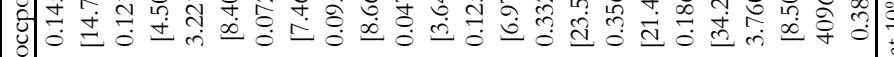

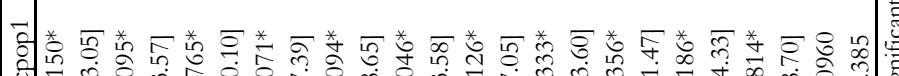

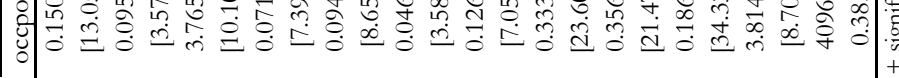

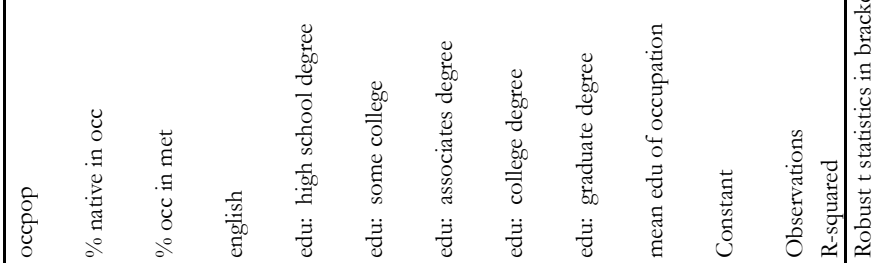

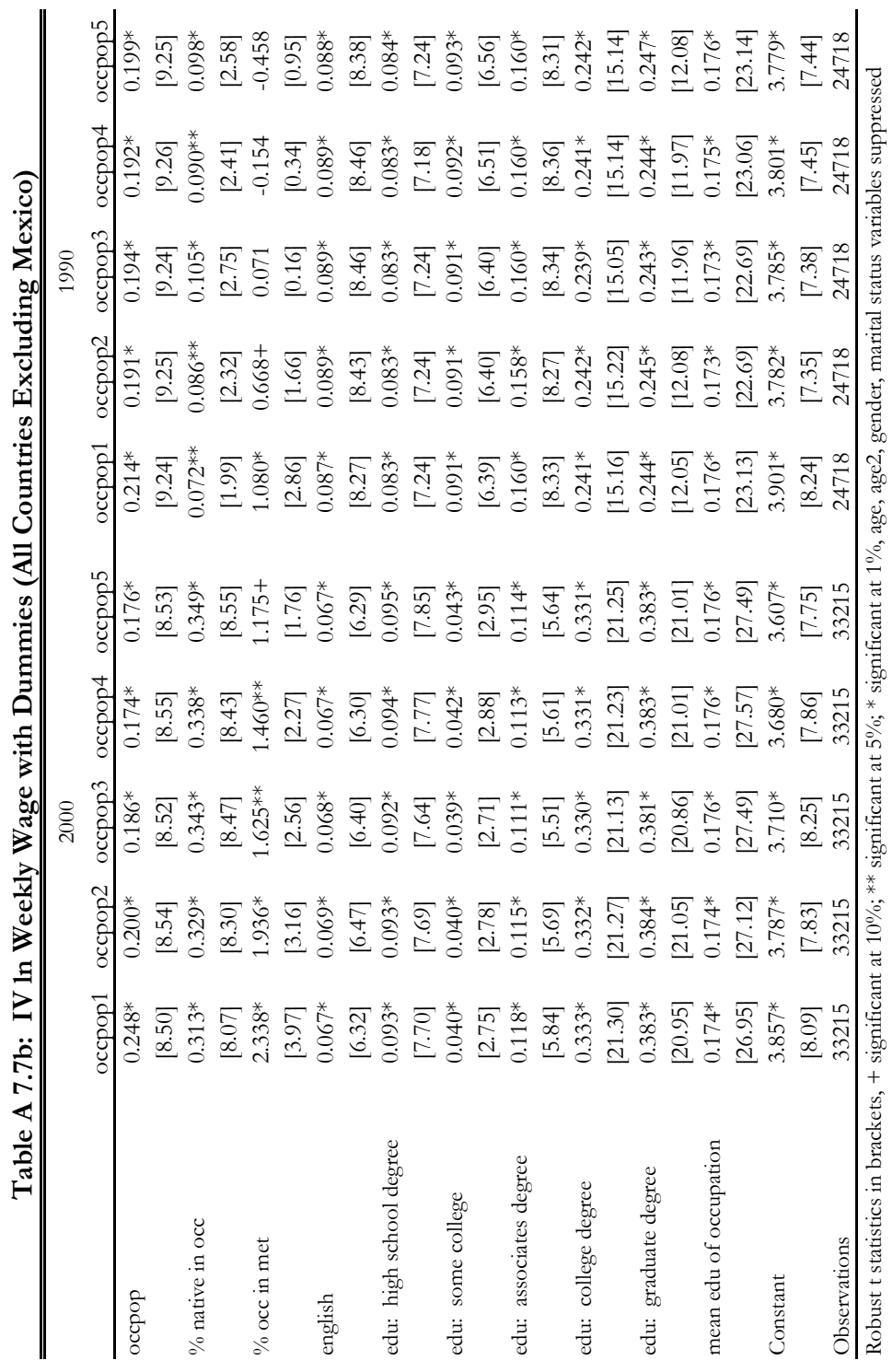




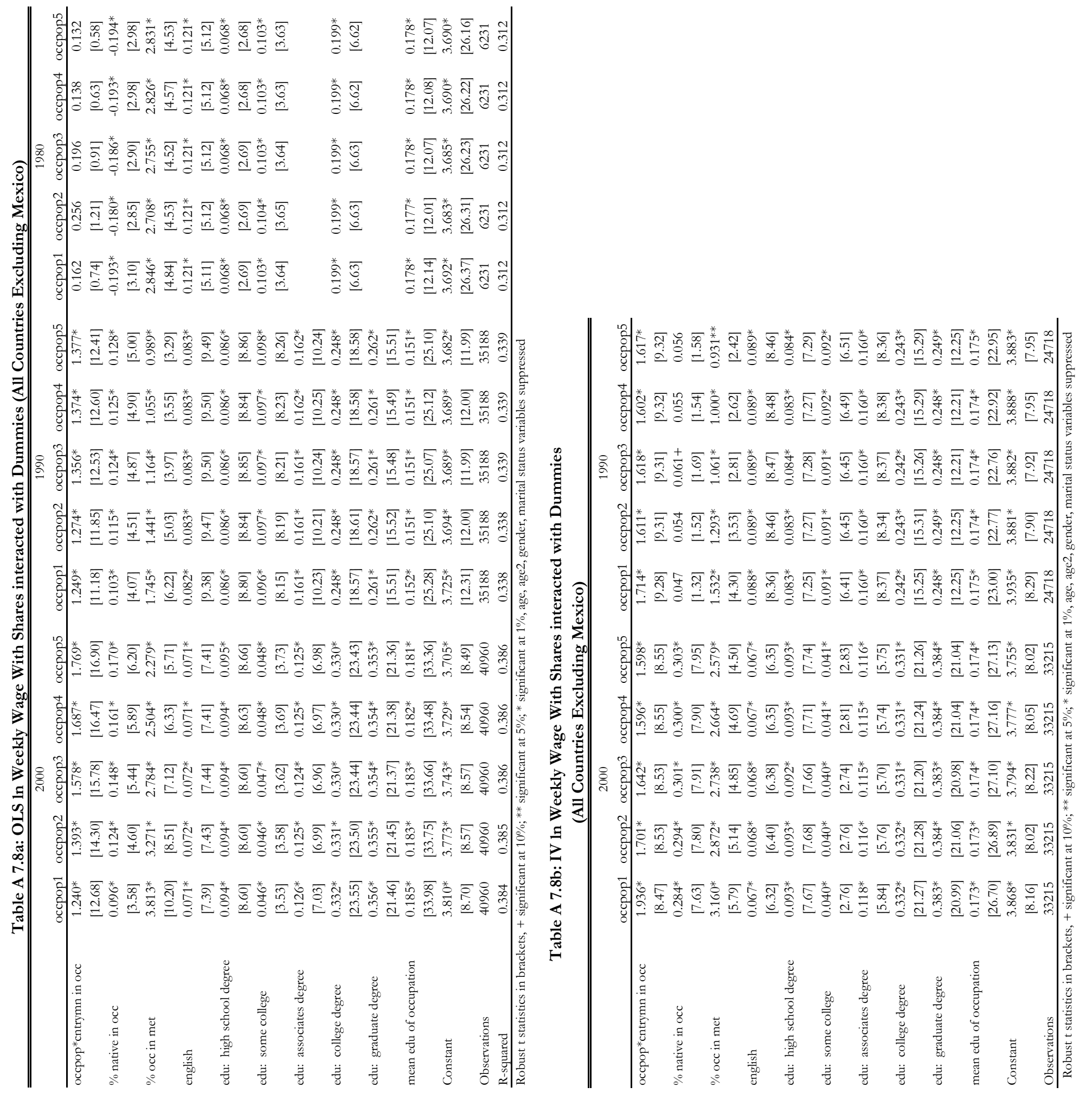

